\title{
A Survey on History the First Women's Hospital in Iran
}

\section{A R T I C L E I N F O}

\section{Article Type}

Historical Original Research

\section{Authors}

Karimian A.* MSC

*Governmental Management Training Center, Tehran, Iran

\section{Correspondence}

Address: Sarem Women's Hospital, Basij Square, Phase 3, Ekbatan Town, Tehran, Iran. Postal Code: 1396956111

Phone: +98 (21) 44670888

Fax: +98 (21) 44670432

ali_karimiyan_2011@yahoo.com

\section{Article History}

Received: March 17, 2016

Accepted: June 21, 2016

ePublished: August 15, 2017

\section{A B S T R A C T}

Aims Modern medicine in Iran during the Qajar period and the Chancellery of Amir Kabir, especially after the establishment of the "Darulfonon", flourished. This school had a variety of majors, including medicine and pharmacy, and with the recruitment of foreign teachers, was a major contributor to the development and teaching of science, including medicine. Then the school graduates, along with teachers, established government hospitals. Also, at that time, some branches of hospitals were assigned to midwifes and tutors in the hospital, which were soon shut down. But in the next years, regarding to the increasing number of high-risk pregnancies and the deaths of women and children, the necessity of establishing a hospital for pediatricians and obstetricians was quite evident. So far, there has been some the sources about the maternity hospital that does not exceed a total of several lines, but in the Qajar periodical archives and publications, as well as internal and external experts' reports, the history of the women's hospital was presented in terms of the process of development and executive organization, financing, development of activities.

Conclusion Dr. Amir Alam in 1915 stated the necessity of establishing a maternity hospital to the Ministry of Education. Thus, the Board of Governors donated a building for the hospital. After the establishment and supply of equipment in 1916, the maternity hospital was opened. From the time of its establishment to 1927, this hospital was under the supervision of Dr. Alireza Mohazzabolsaltaneh. Women's Hospital as the first special treatment center for women and children in Iran was the base of other health centers, and treatment programs for women and children in the country.

Keywords Hospital; Women; Midwives; Nurses

\section{CIT A T I O N L I N KS}

[1] Analytical report of 4 year performance: on the occasion of the 70 th year of establishment of the Terhran University of Medical Sciences 1934-2009 [2] Pars Annual [3] The history of military medicine [4] Madam Carla serena's itinerary in Iran [5] Sina hospital in the course of time [6] TalimolGhavabel: Midwifery training in Qajar [7] Aramaghan-e Javid or Doctor Aalam's Biography [8] Untitled [9] A glance to charirty affairs in Qajar Era [10] History of medicin in Iran [11] National Library And Archives Of Iran. Accession No 24094406 [12] Research in the history of Imam Khomeini Hospital [13] Science and education and culture Ministers of Iran [14] History of New Civilization Institutions in Iran [15] Preparations for Qajar dethronment and Reza-Khan's coronation by audigheh one the Darul-Funun, French teachers and ms. dermps, Former student of the Eastern languages school [16] National Library And Archives Of Iran. Accession No.297043704 [17] National Library and Archives of Iran. Accession No.297011414 [18] National Library and Archives of Iran. Accession No.240009267 [19] Calendar of Iran's contemporary history [20] National Library and Archives of Iran. Accession No.2400032562 [21] National Library and Archives of Iran. Accession No.240095867 [22] National Library and Archives of Iran. Accession No.113009. Row No.54422 [23] National Library and Archives of Iran. Accession No.113009. Row No.52431 [24] Iran's health situation report in Iran [25] National Library and Archives of Iran. Accession No.29728655 [26] National Library and Archives of Iran. Accession No.103004. Row No.6368 [27] NNational Library and Archives of Iran. Accession No.103004.Row No.6349 [28] National Library and Archives of Iran. Accession No.103004. Row No.6443 [29] Statistics Annual, 1938-1939 [30] Modern health in Iran [31] Nadereh karan (mourning letter for Cultural and literary renowneds) 1925-2002 [32] The Biography the famous cantemporary Iranian physicians [33] A Comprehensive dictionary of Contemporary Iranian and mititary Personalities 
شعبهاى براى تربيت قابلهها و طبيبهها در مريض آنانه داير شد،

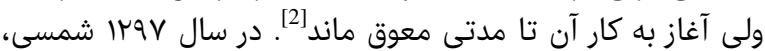

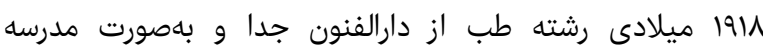

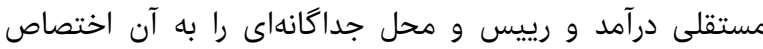

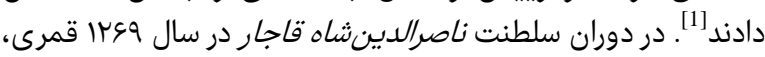

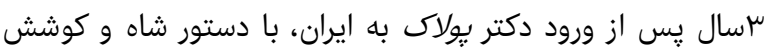

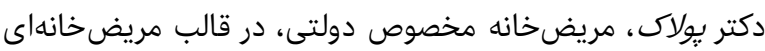

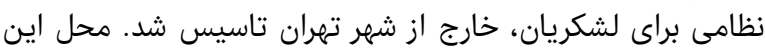

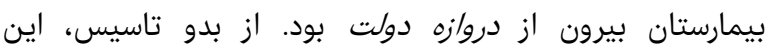

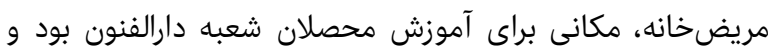

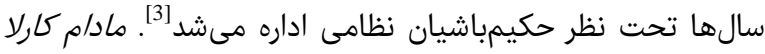

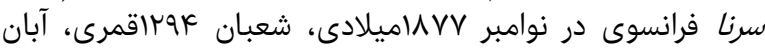

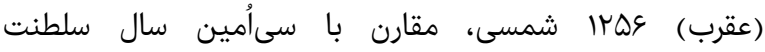

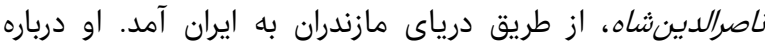

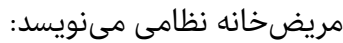

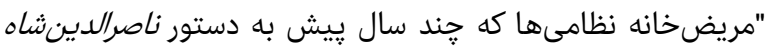

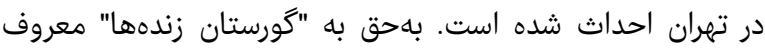

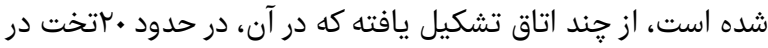

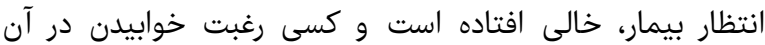

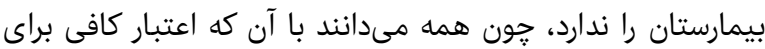

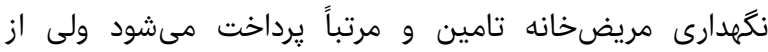

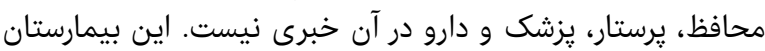

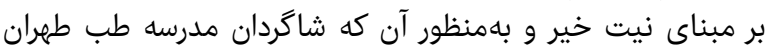

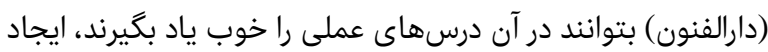

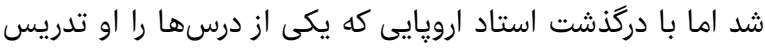

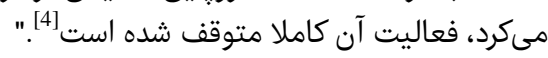

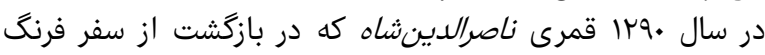

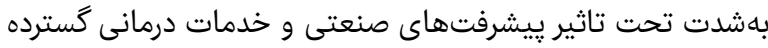

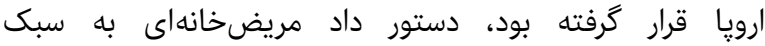

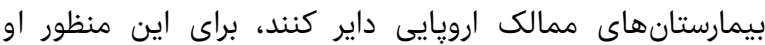

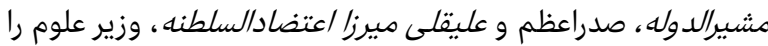

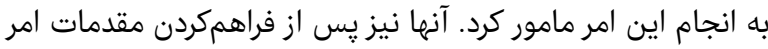

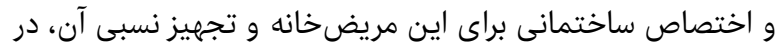

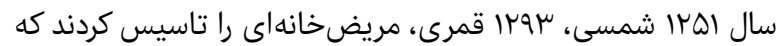

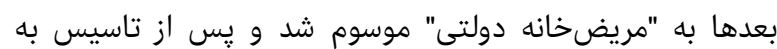
مدت هسال، دكتر على اكبرخان نفيسى (ناظم/الاطبا )عهدهدار رياست

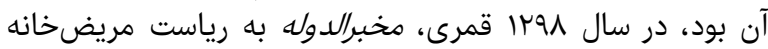

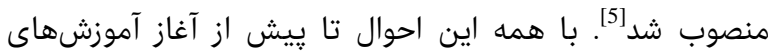

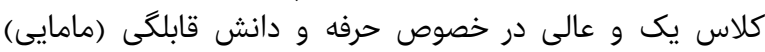

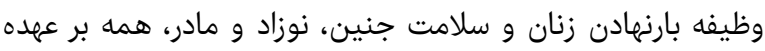

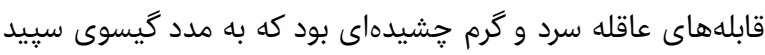

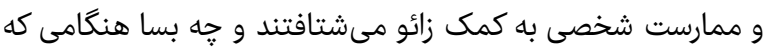

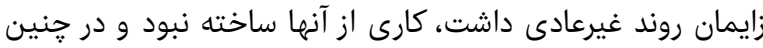

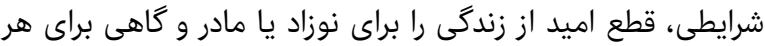

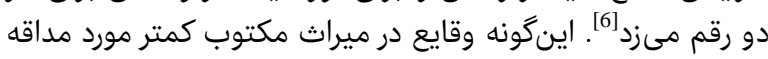

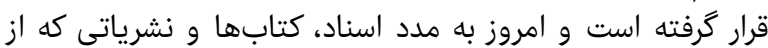

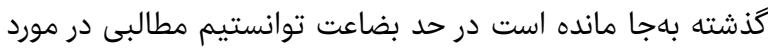

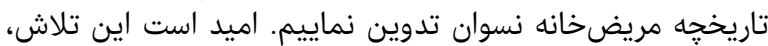
فتح بابى براى يزوهش مهائ درخور تدور آتى باشد.

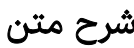

در سال هrسا قمرى دكتر /ميراعلم رييس مجلس حفر حفظالصحه دولتى، (تصوير ) به قصد زيارت آستان قدس و و سركشى به
مرورى بر تاريخجه مريض خانه نسوان (بيمارستان

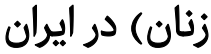

ملى كركز آموزش مديميان*

جكيده

مقدمه: طب نوين دره ايران در زمان قاجاريه و صدراعظمى /ميركبير، بهخصوص

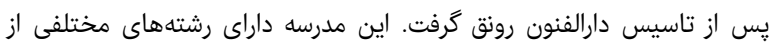

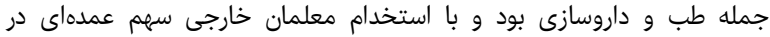

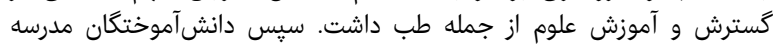

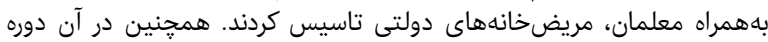

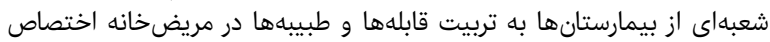

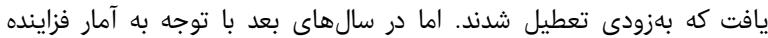

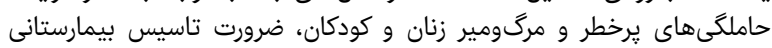

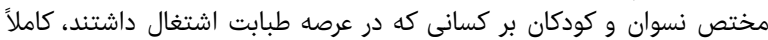

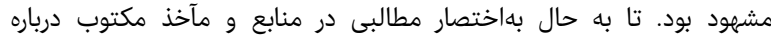

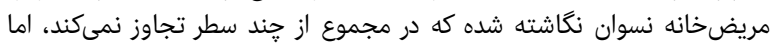

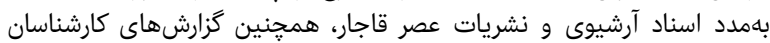

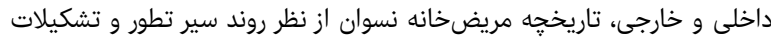

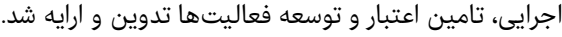

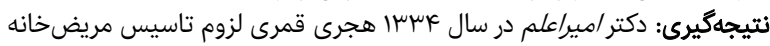

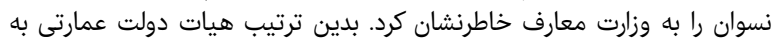

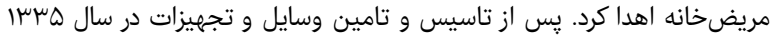

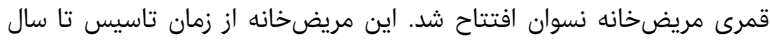

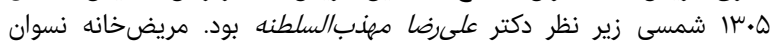

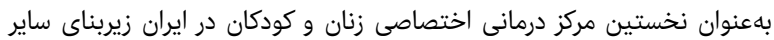

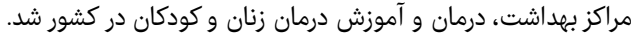

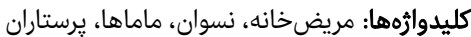

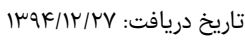

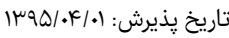

ali.karimian1342@gmail.com : تويسنده مسئئوش:

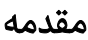

طب نوين در ايران در زمان قاجاريه و با ظهور مييرزا تقىخان

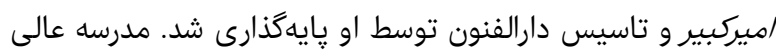

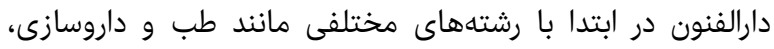

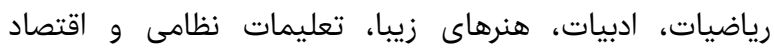

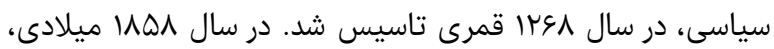

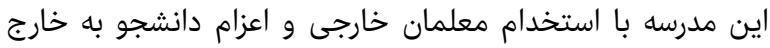

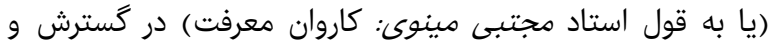

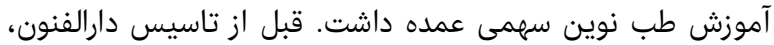

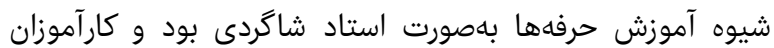

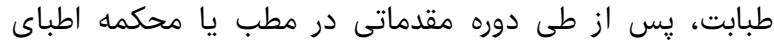

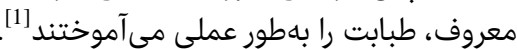

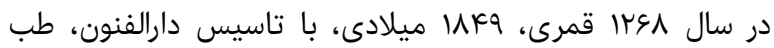

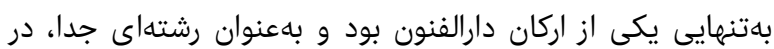

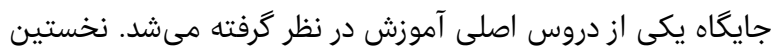

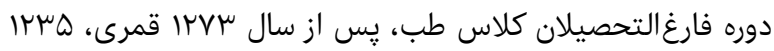

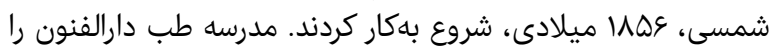

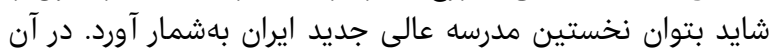

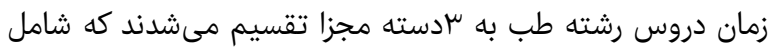

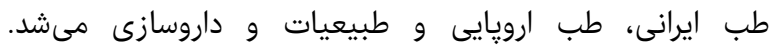

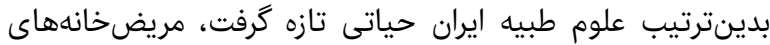
دولتى تاسيس شدند و محصلان عملاً با طب جدئ كريد آشنا شدناندان 


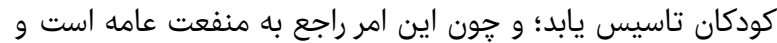

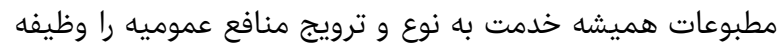

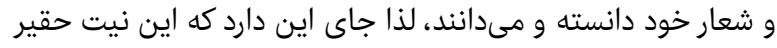

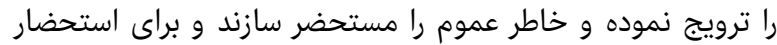

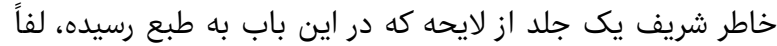
تقديم مىنمايد"]

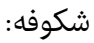

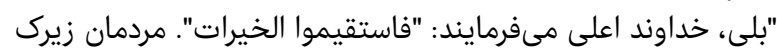

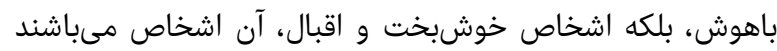

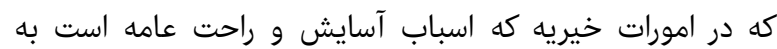

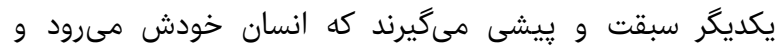

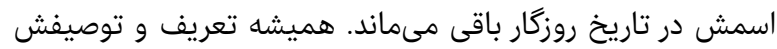

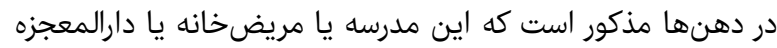

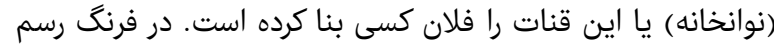

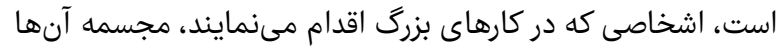

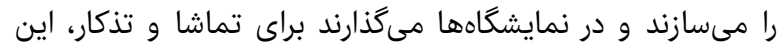

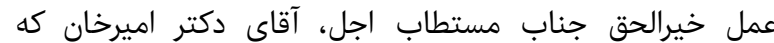

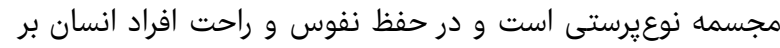

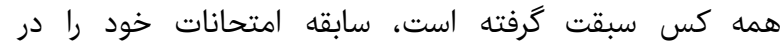
اقسامالخيرات و ميراث به همه كس نمايش دابثه دادهاند. اولاً در فقره

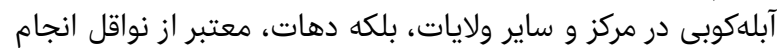

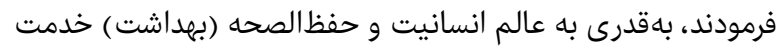

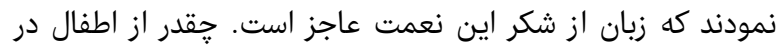

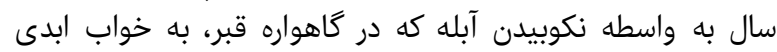

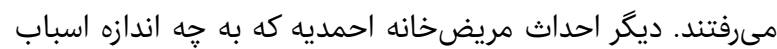

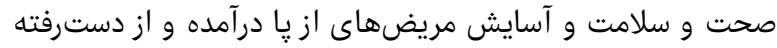

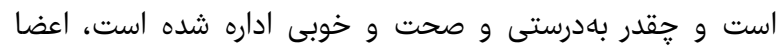

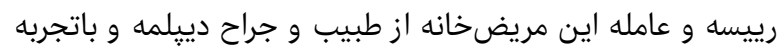

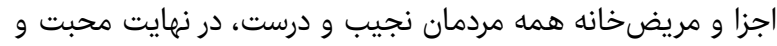

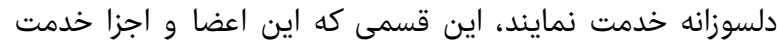

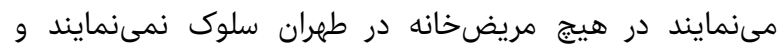

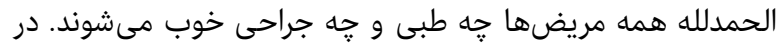

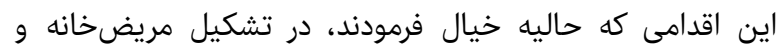

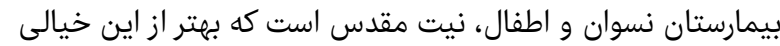

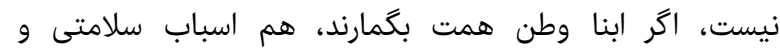

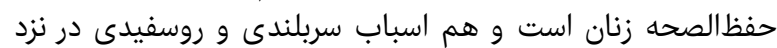

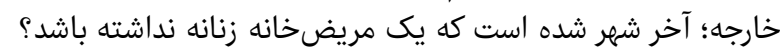

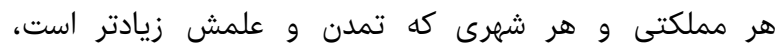
مريضخانهاش بيشتر است. شهرى كه مريض فرى

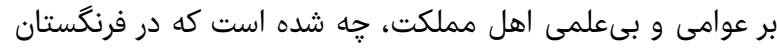

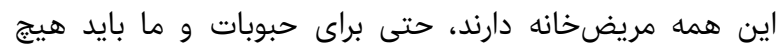

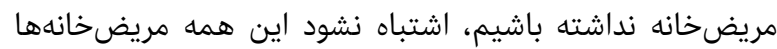

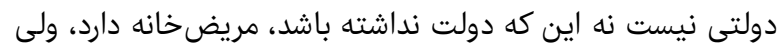

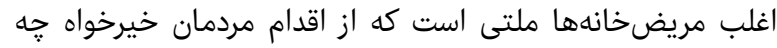

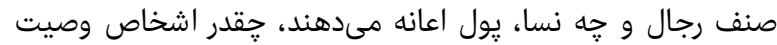

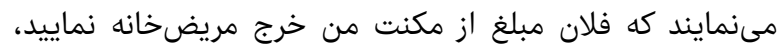

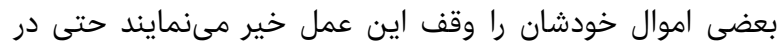

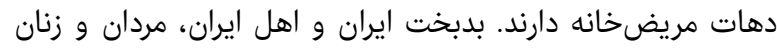

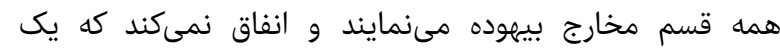

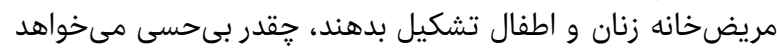

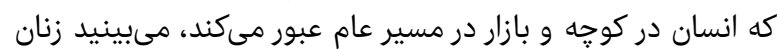

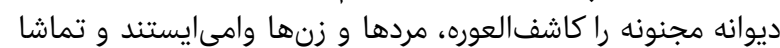

موسسات بهدارى و صحى مشهد، راهى آن ديار شد. در بازديد از

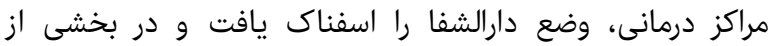

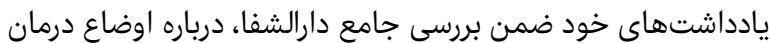
زنان مطالبى نكاشت.

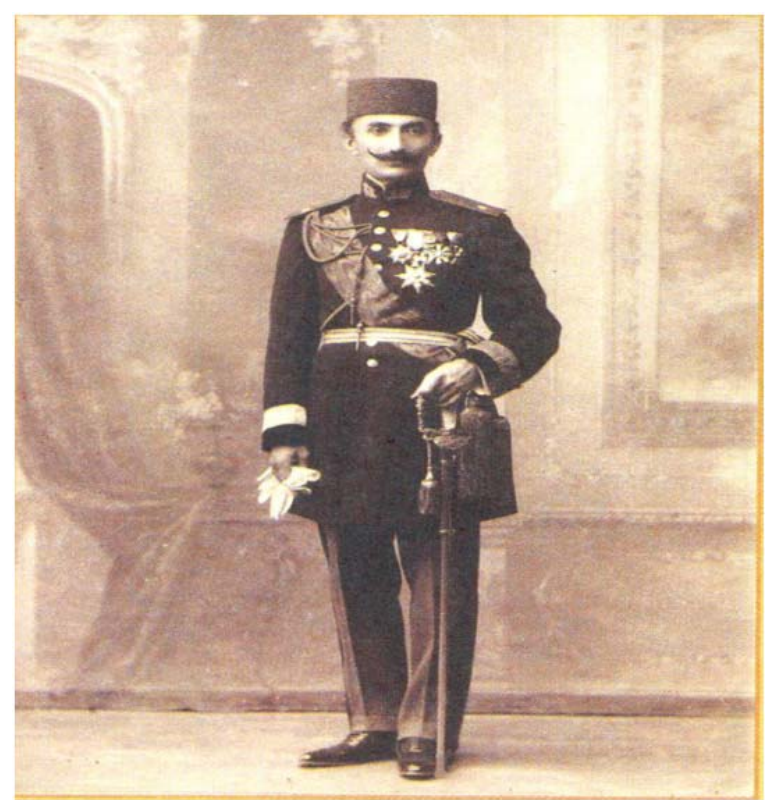

تصوير () دكتر اميراعلم، رييس مجلس حفظ الصحه دولتى، دوره قاجار

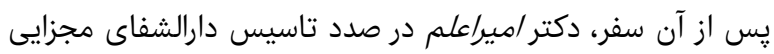

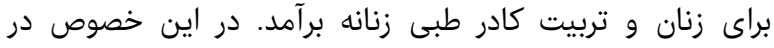
نوشتههاى او آمده است: "براى شعبه زنان در فكر خواستن طبيبه و است جراحه و قابله هستم كه

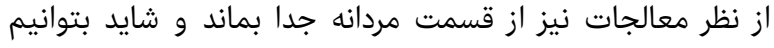

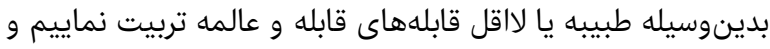

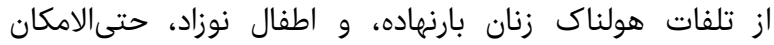

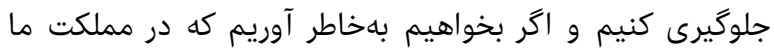

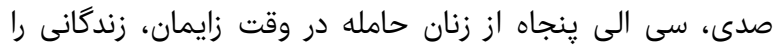

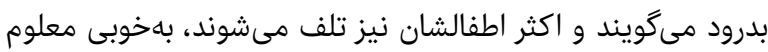

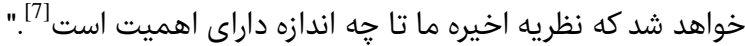

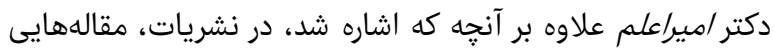

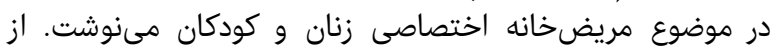

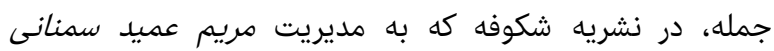

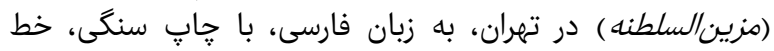

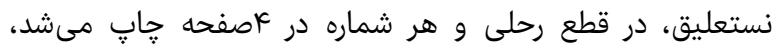

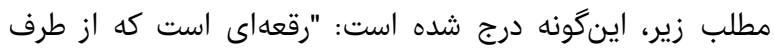

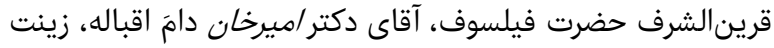

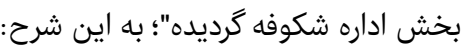

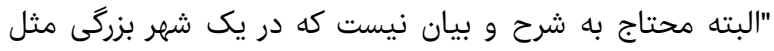

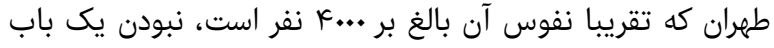

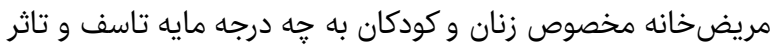

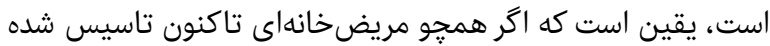

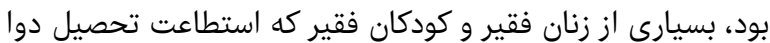

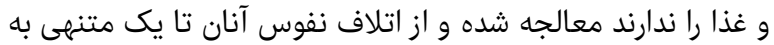

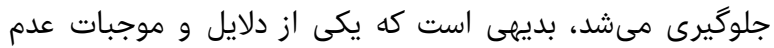

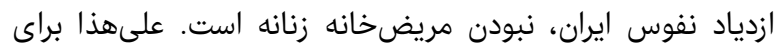

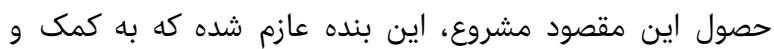
مساعدت هموطنان اعزاز، يكباب مريض مضرو، بنده عانه مخصوص به به زنان و 


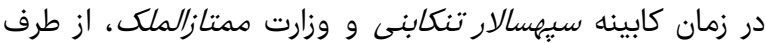

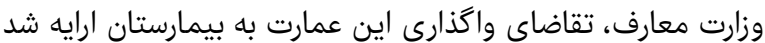

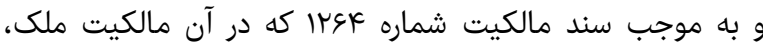

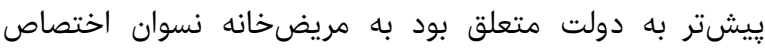

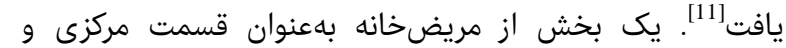

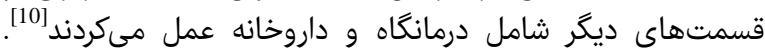

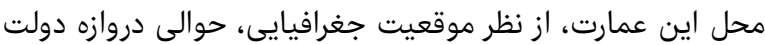

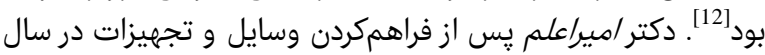

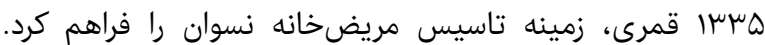

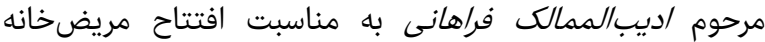

شاهى كه به عهد داستان است

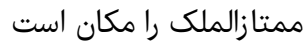

كز كردارش هنر عيان است است است

كاسايش ملتى در آن است است

زين كاخ شفا به رايكان است است است

بيمارستان بانوان است است

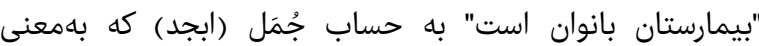

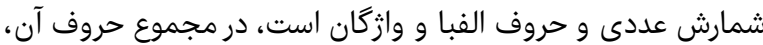
سال تاسيس بيمارستان نسوان يعنى سال هسرّا قمرى را را بهدست

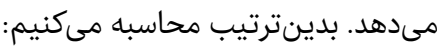

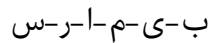
e.-r.*-1-K.-1.-r ت $\Delta \cdot-1-K$. ب$\omega \cdot-\mid-S-\omega \cdot-r_{-1}$ - -1 r.*-s.-1 $1 \mu m \omega=$

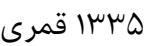
مريض حانه نسوان زير نظر دكتر عليرضا مهذبالسلطنه (پسرعموى

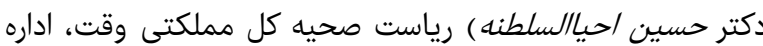

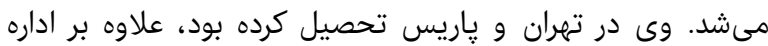

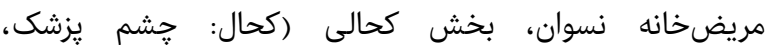
Ophthalmobgist, (Oculist)

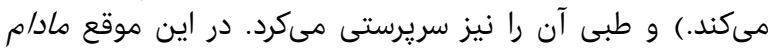

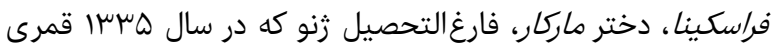

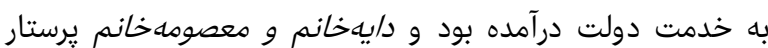

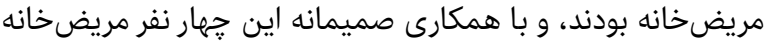

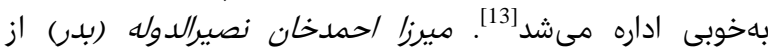

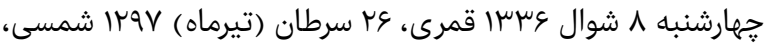

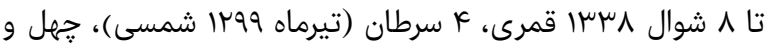

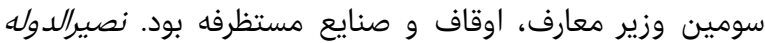

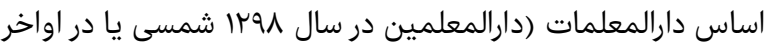

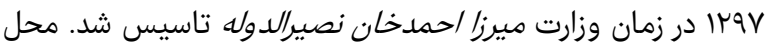

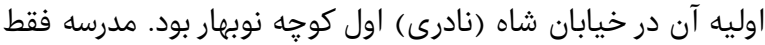

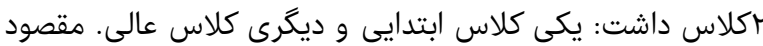

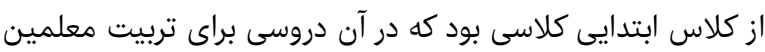

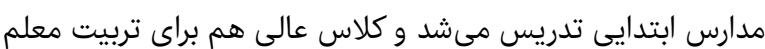
براى دبيرستانها بود. بعد از اين محل مدرائ مدرسه به به عمارت شرات شركت

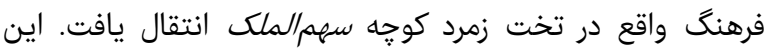

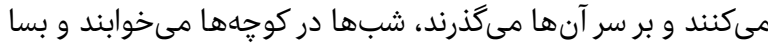

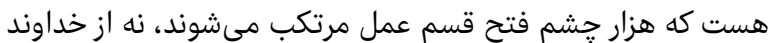

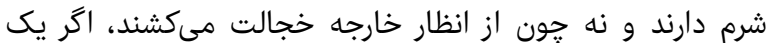

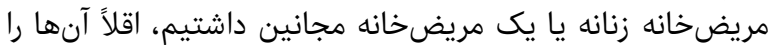

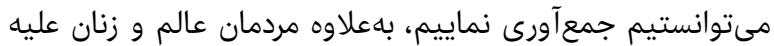

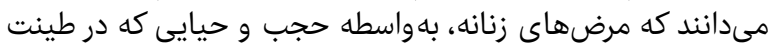

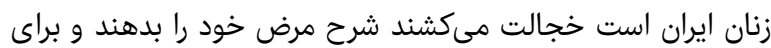

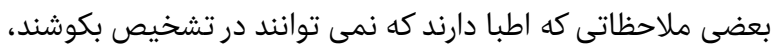

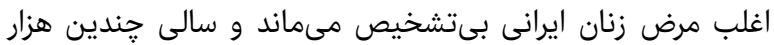

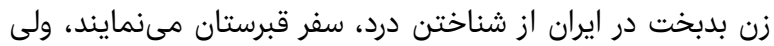

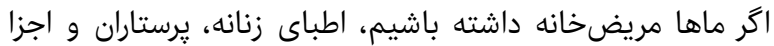

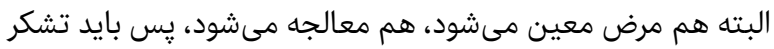

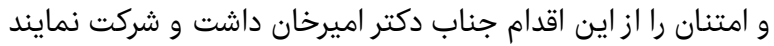

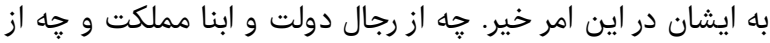

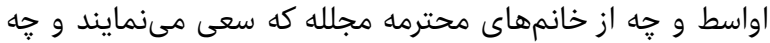

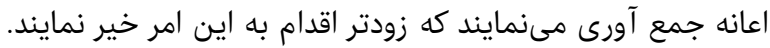

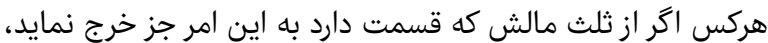

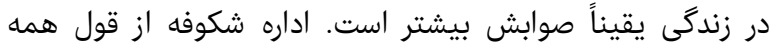

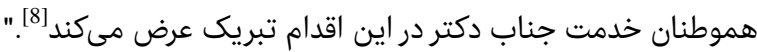

تاسيس مريض خانه نسوان

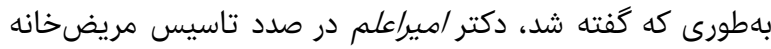

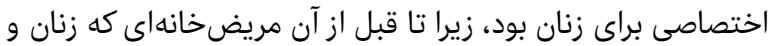

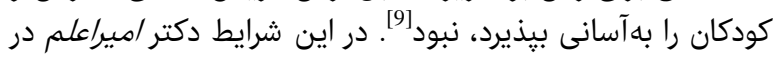

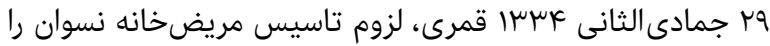

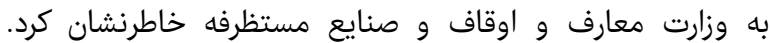

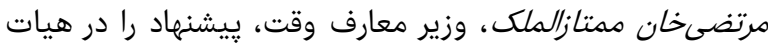

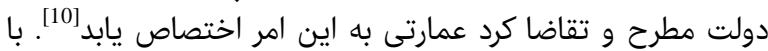

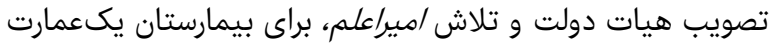

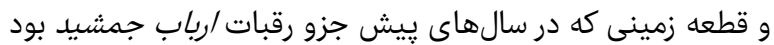

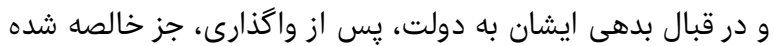

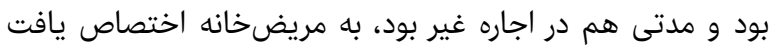

(تصوير r).

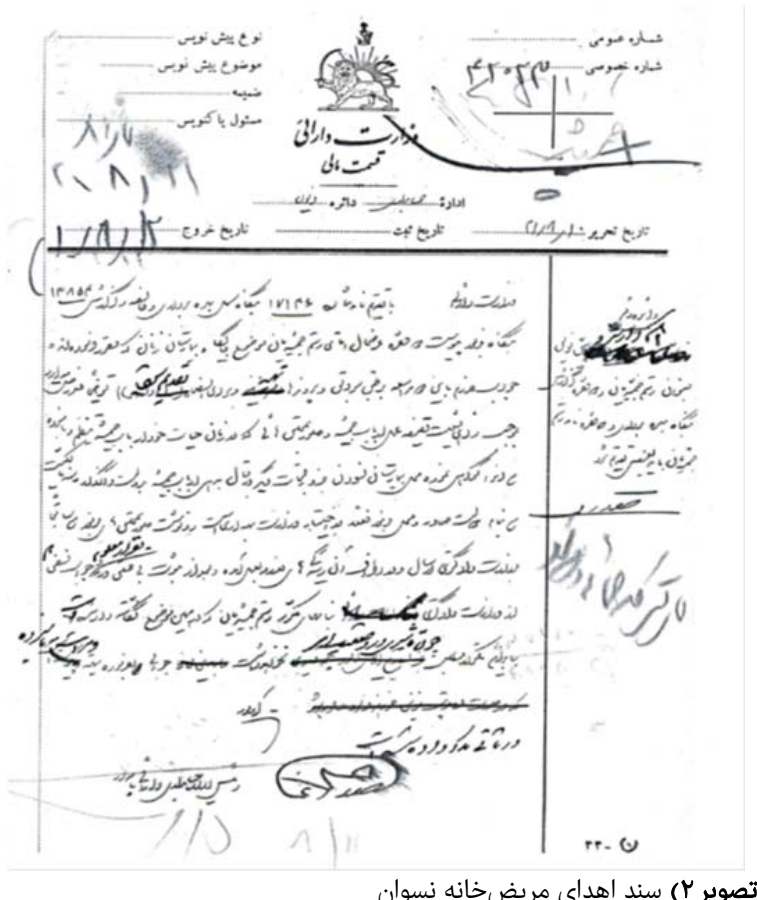

تصوير Y) سند اهداى مريض خانه نسوان 


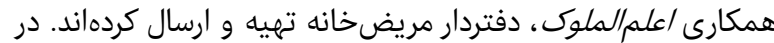

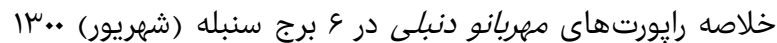

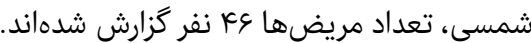

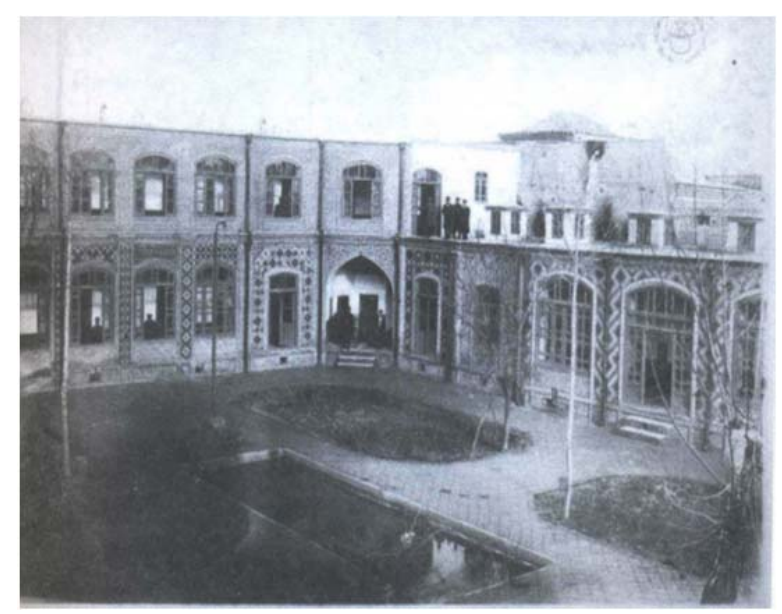

تصوير F) مريضخانه نسوان، •."ساشمسى

همجنين در اين گزارش در اعتراض به رفتار مادموازل دِرُمِس نوشته شده است:

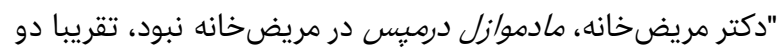

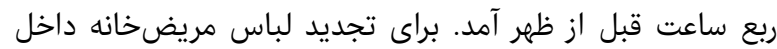

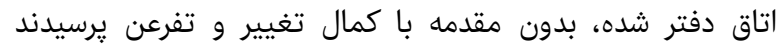

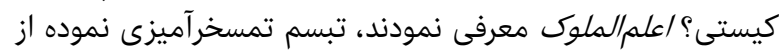

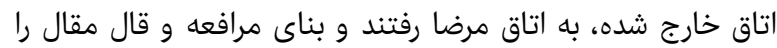

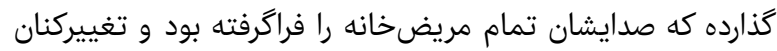

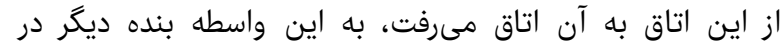

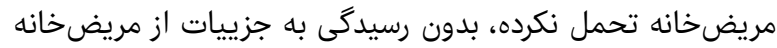

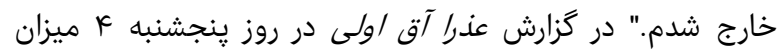

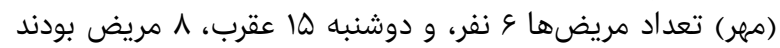

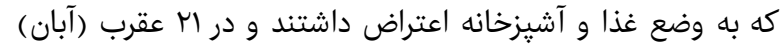

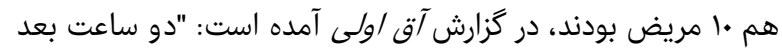

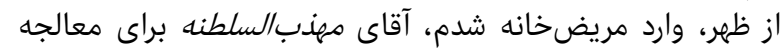

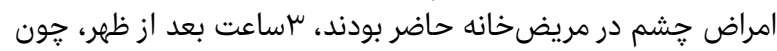

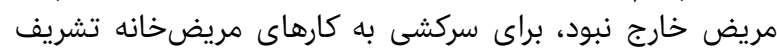

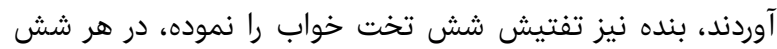

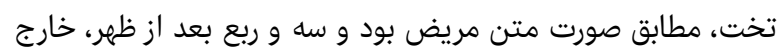

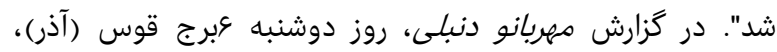

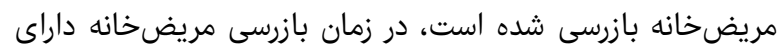

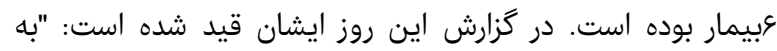

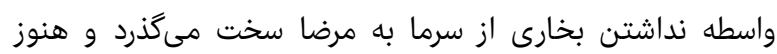

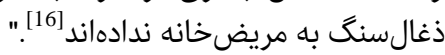

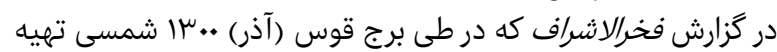

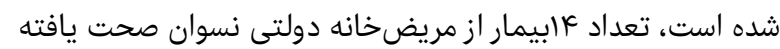

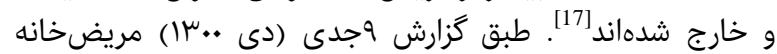

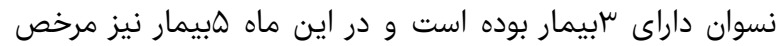

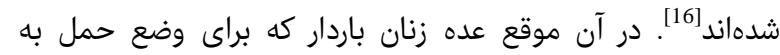

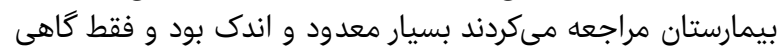

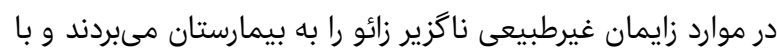

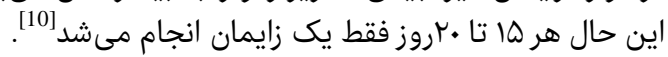

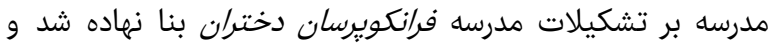

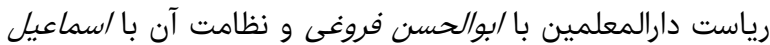

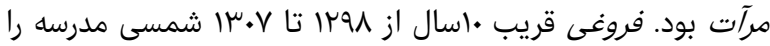

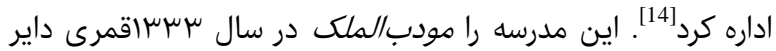

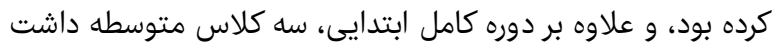

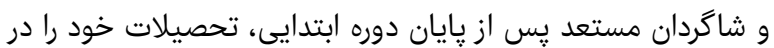

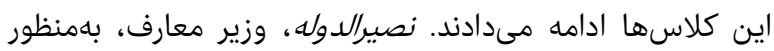

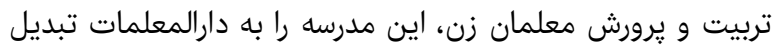

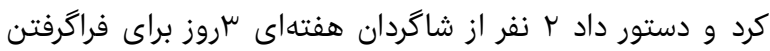

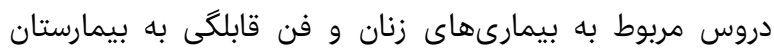

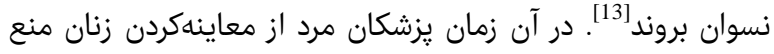

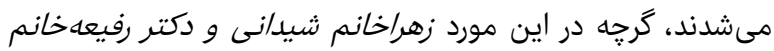

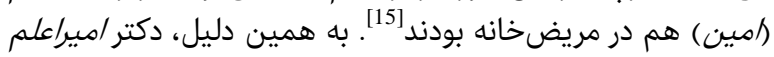

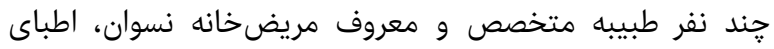

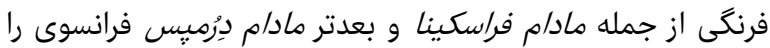

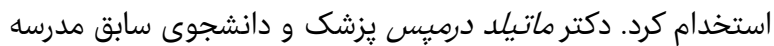

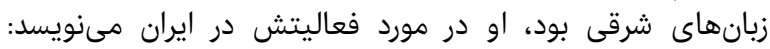

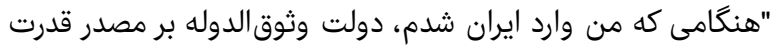

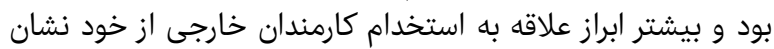

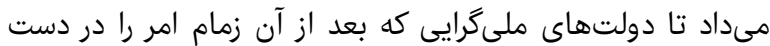

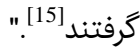

دكتر بن و دكتر سركيسيان كه در قابلكى و بيمارىهاى زنان

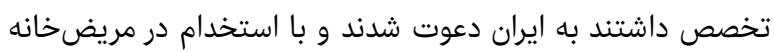

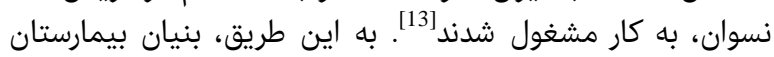
نسوان گذاشته شد (تصوير س) مان.

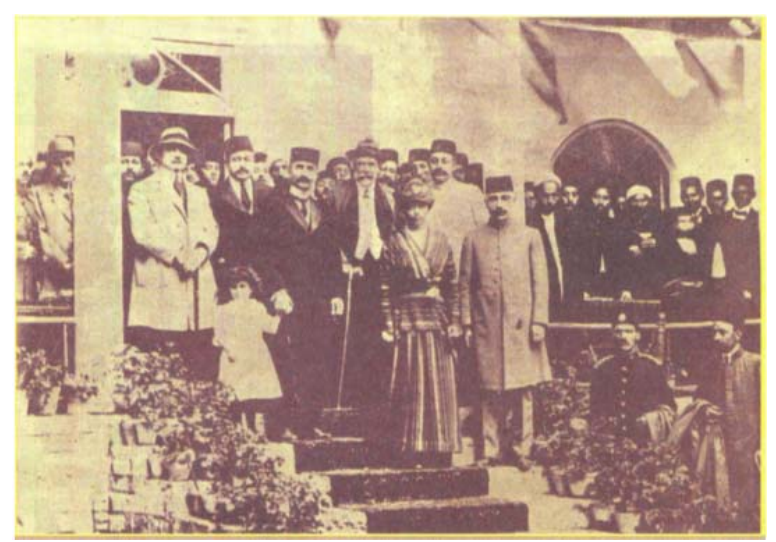

تصويرسّ) مراسم افتتاح مريضخانه نسوان، دوره قاجاريه

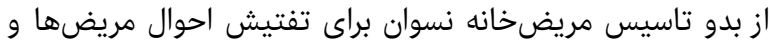

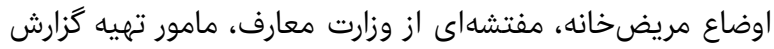

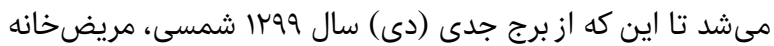

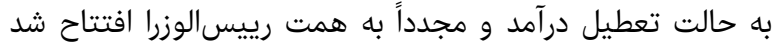

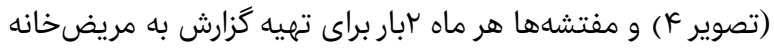

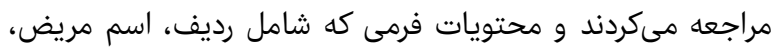

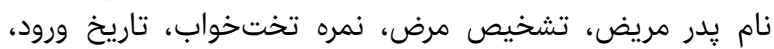

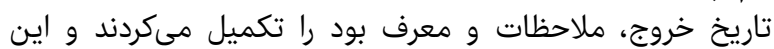

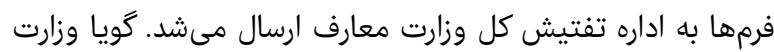

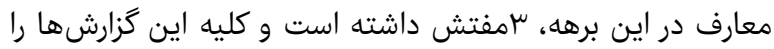

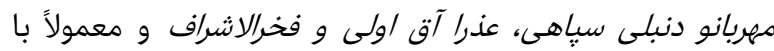




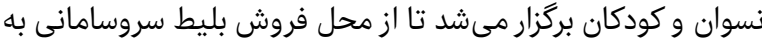

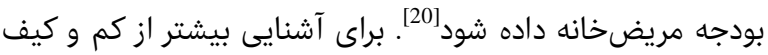

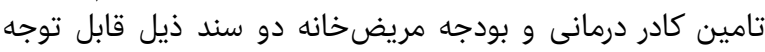

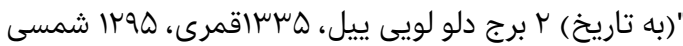

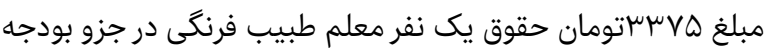

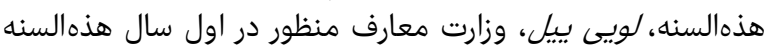

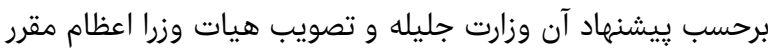

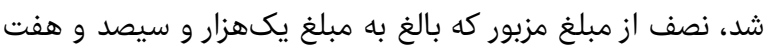

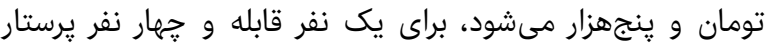

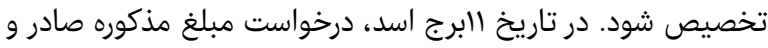

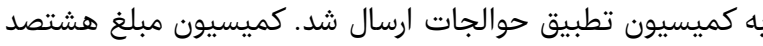

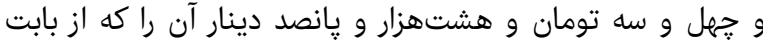

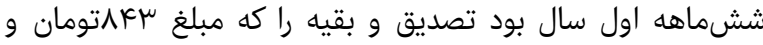

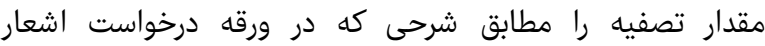

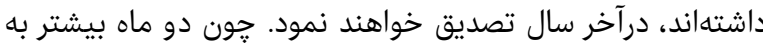
آخر سال نمانده [است]

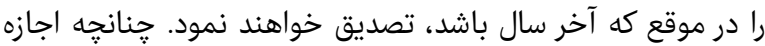

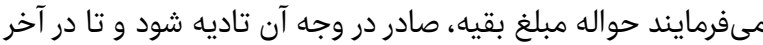
سال، ورقه درخواست براى تصديق به كميسيون ارسال شود. منوط آنا دارد

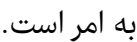
[حاشيه:] اينجا تصريح نشده است كه ششماهه اول ئر يرداخته شده

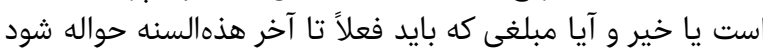

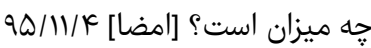

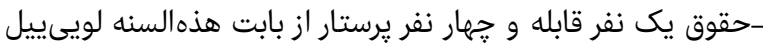
كAV/D

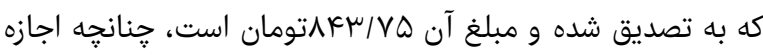

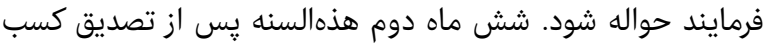

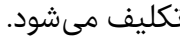
- ششماهه اول هذهالسنه حواله شود. وزارت معارف و اوقاف، اداره محاسبات، دايره مراسلات، نمره

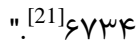

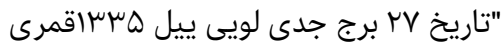

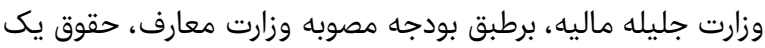

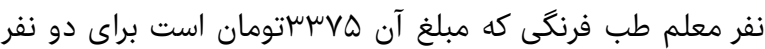

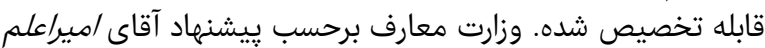

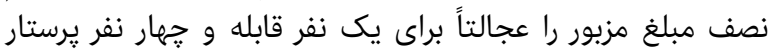

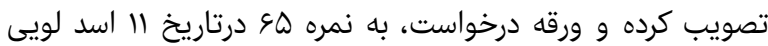

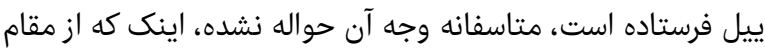

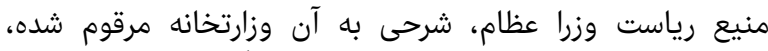

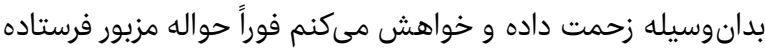

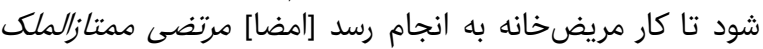

[مهر] وزارت معارف، اوقاف و صنايع مستظرفه، رياست وزرا ، نمره إس

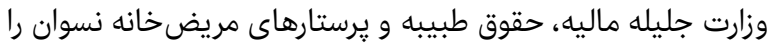

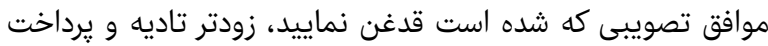
و وسايل آسايش آنها را فراهم نمايند. [ [مُهر] رياست وزرا آسايثر آنها

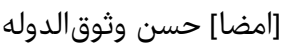
[حاشيه:] اداره محاسبات اططلاعات خود را مرقوم دارند. ا

\section{تجهيزكردن مريضيضان تانه نسوان}

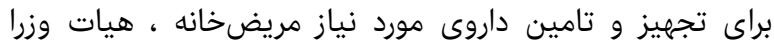

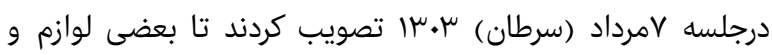

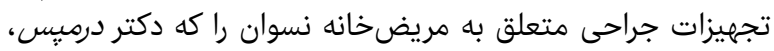

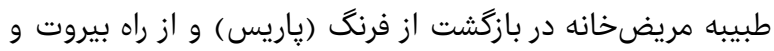

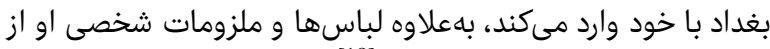

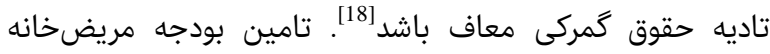

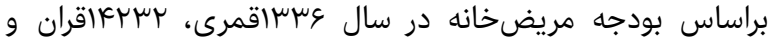

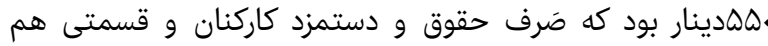

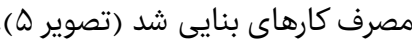

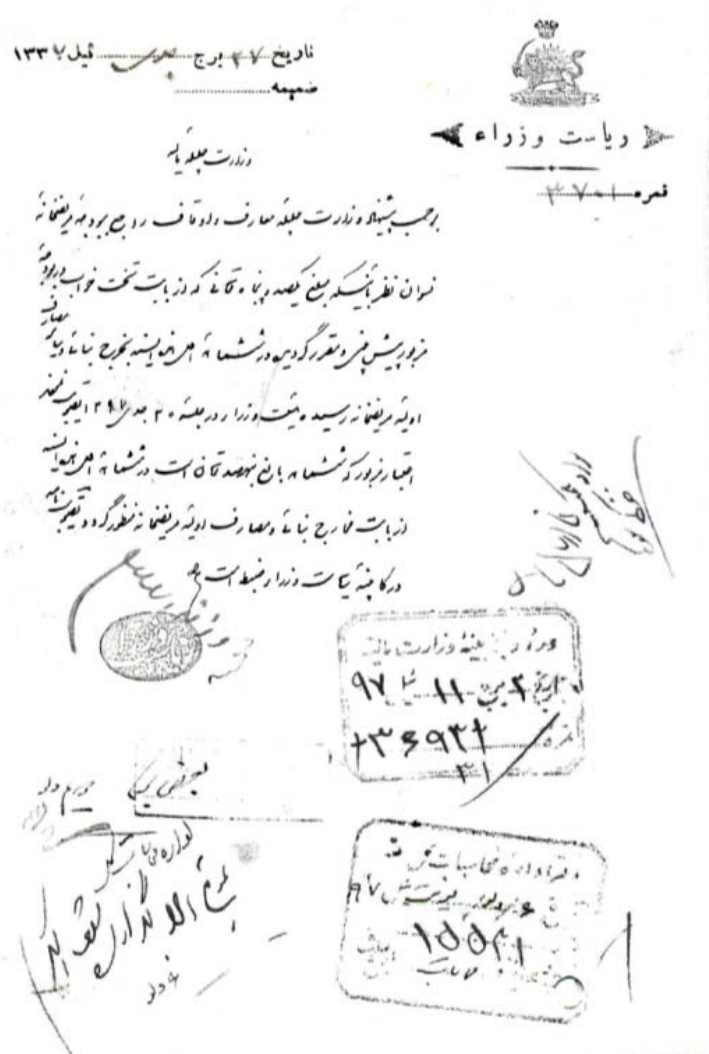

تصوير ه) سند تامين اعتبار مريضخانه نسوان توسط وثوقالدوله (رييس الوزرا)

بدينترتيب از بابت مواجب هماهه: حسن خان خواجه، دrdاقران،

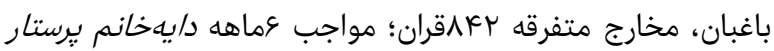

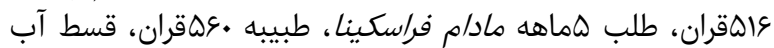

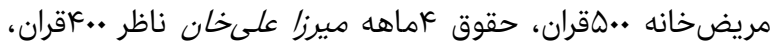

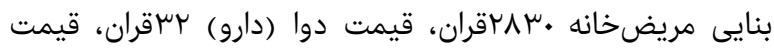

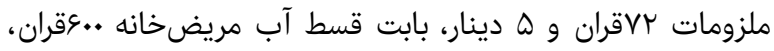

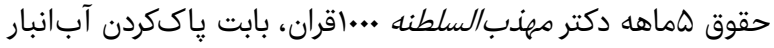

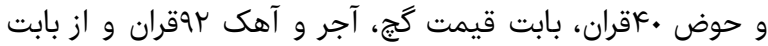

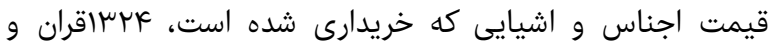

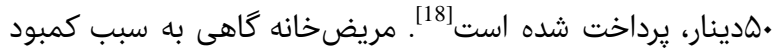

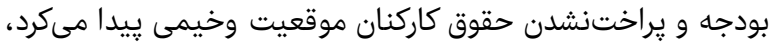

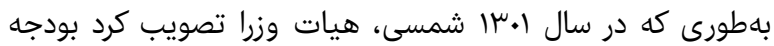

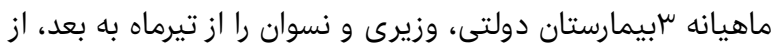

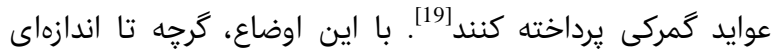

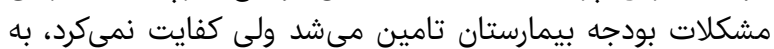
همين سبب در سالهاى بعد برنامه شبنشينى به به نفع مريض كفايت نيكردانه به 


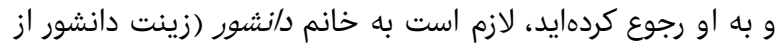

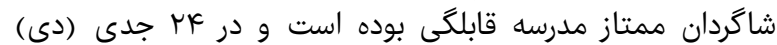

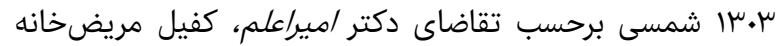

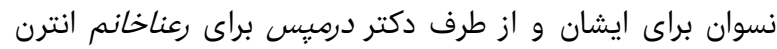

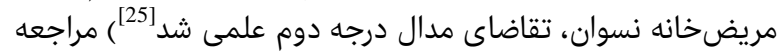

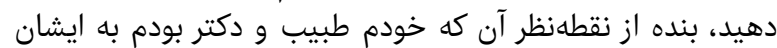

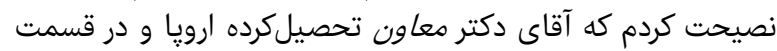

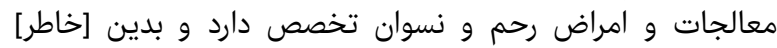

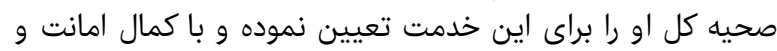

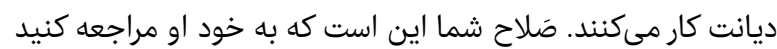

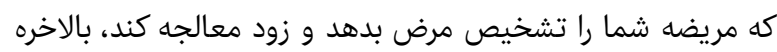

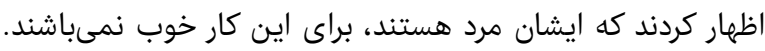

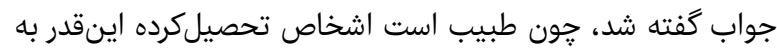

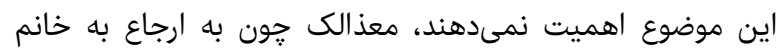

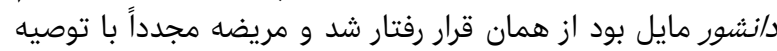

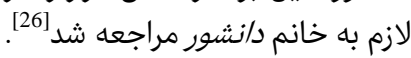

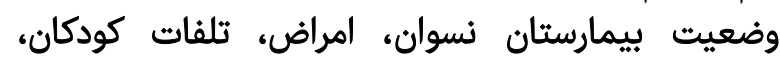
دواسازى و قابلهها، يرستاران و غيران

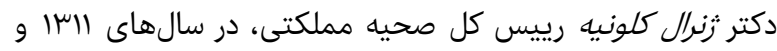

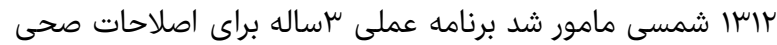

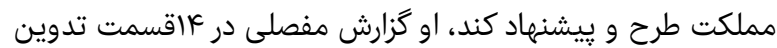

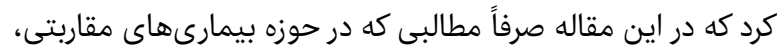

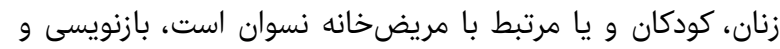

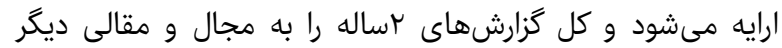

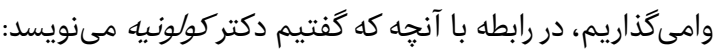

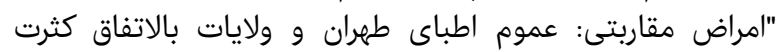

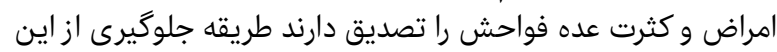

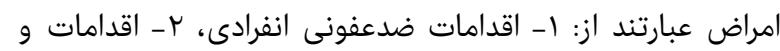

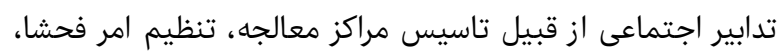

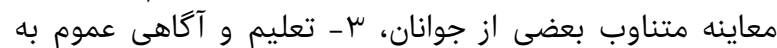

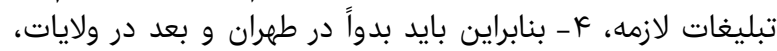

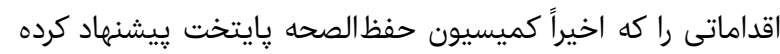

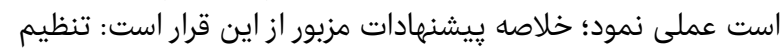

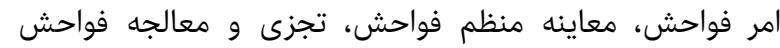

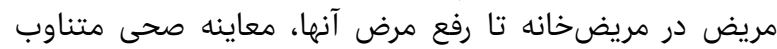

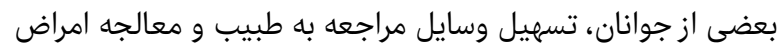
مقاربتى، دادن نصايح و دستورهاى حفظ تسان الصحه به به مردم.

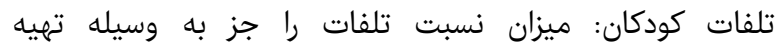

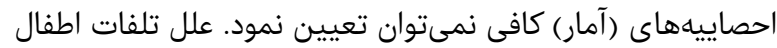

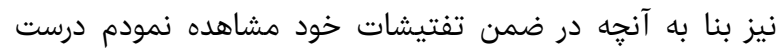

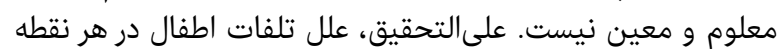

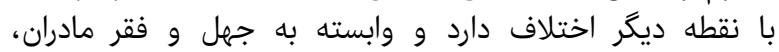

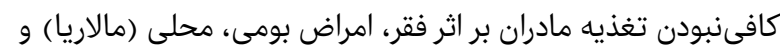

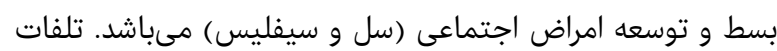

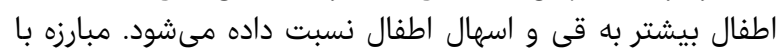

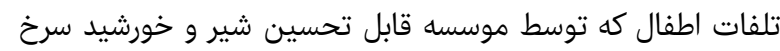

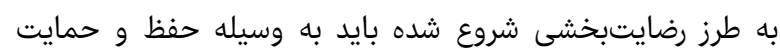

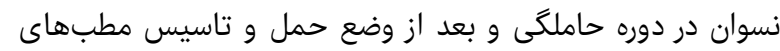

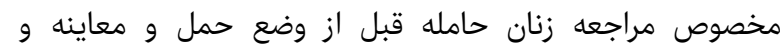

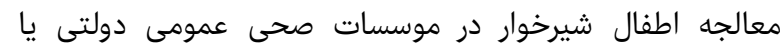
غيردولتى توسعه يابد.
بررسى وضعيت مريضخانه نسوان در گزارش گيلمور

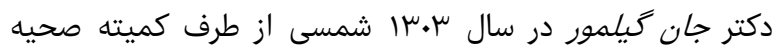

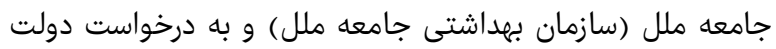

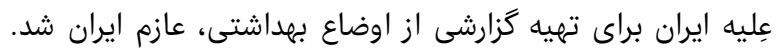

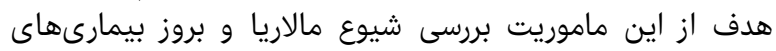

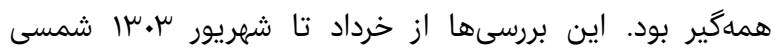

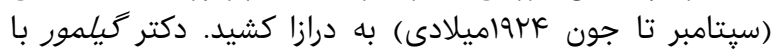

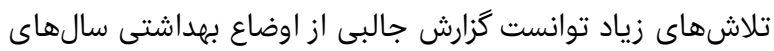

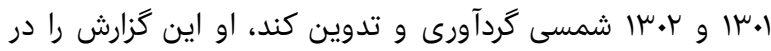

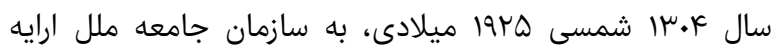

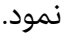

دكتر گيلمور درخصوص مريض خانه زنان مىنويسد:

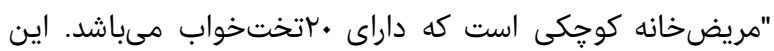

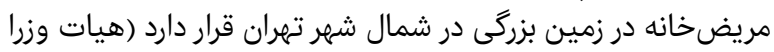

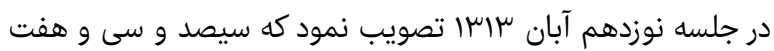

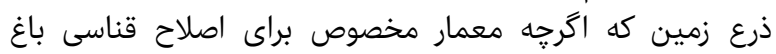

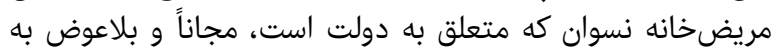

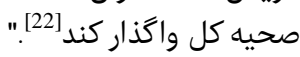

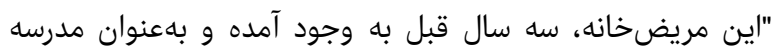

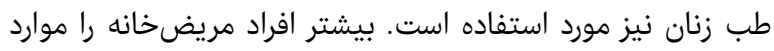

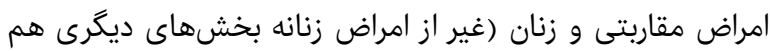

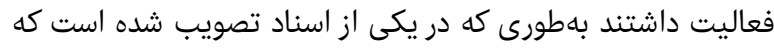

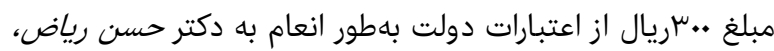

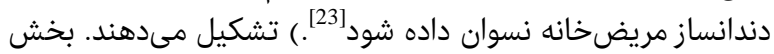

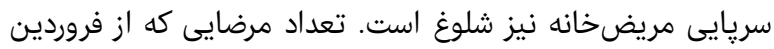

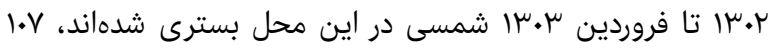

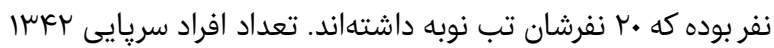

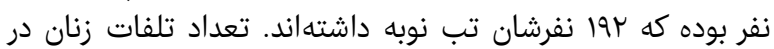

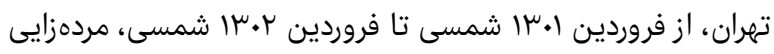

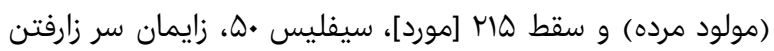

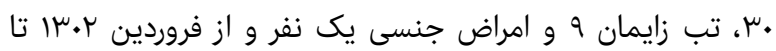

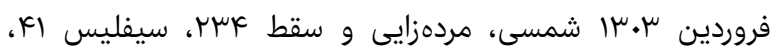

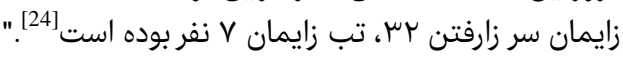

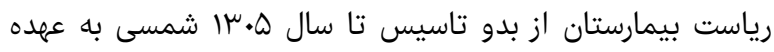

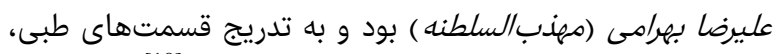

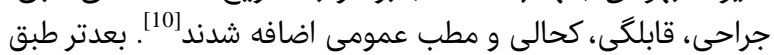

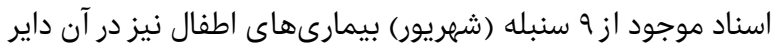

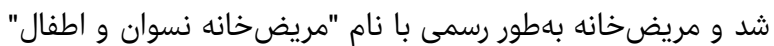

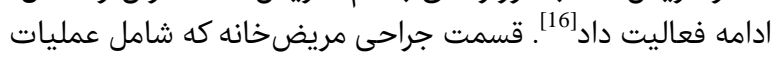

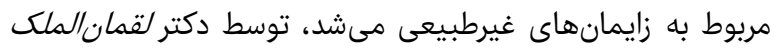

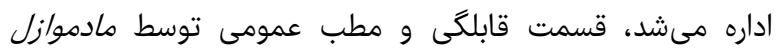

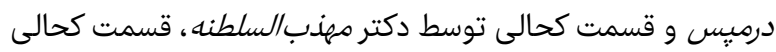

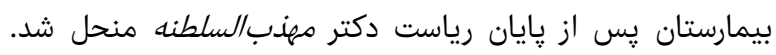

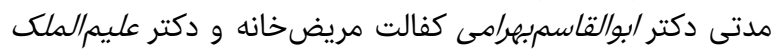

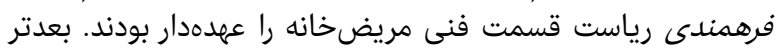

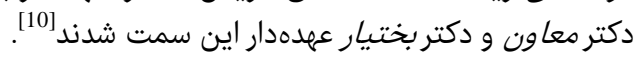

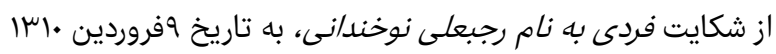

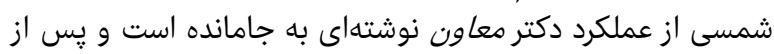

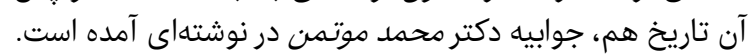

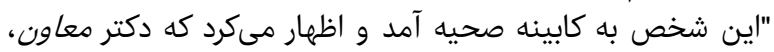
دكتر مريضخانه نسوان، خوب طبيبى نيست كه مه مريضه آمد مرا به آنجا 
مىدانم مجدداً در باب ضرورت و فوريت ساختمان مريض إنانه

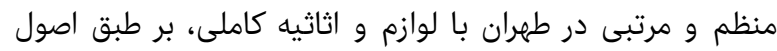

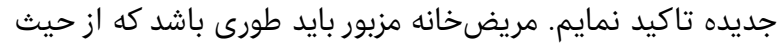

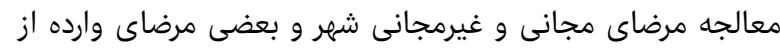

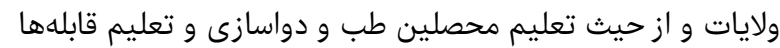

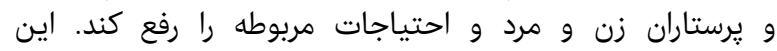

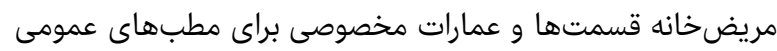

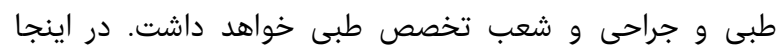

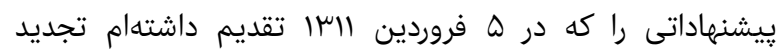

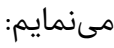

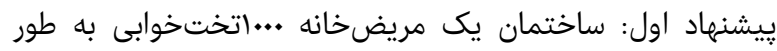

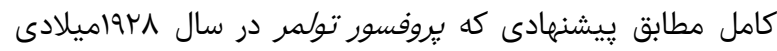

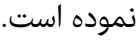

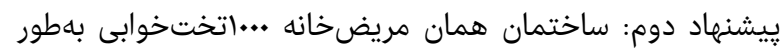

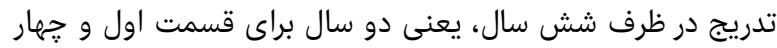
سال براى ساير قسمتها.

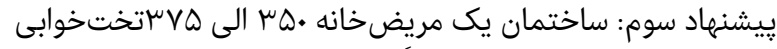

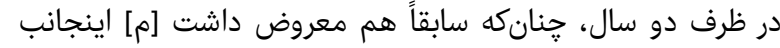

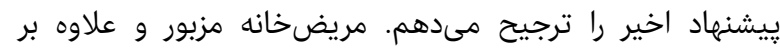

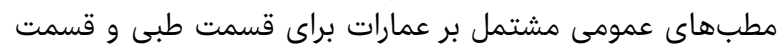

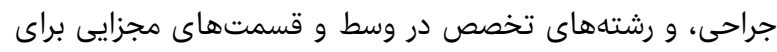

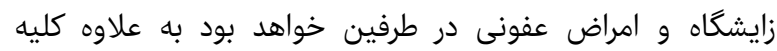

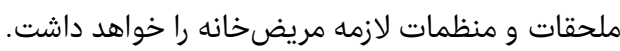

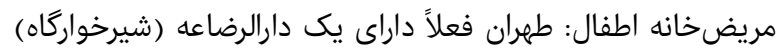

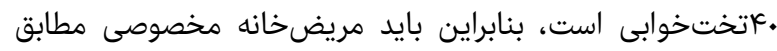

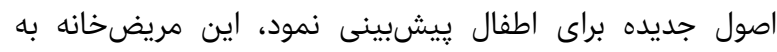

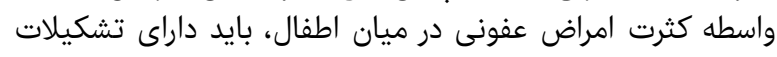

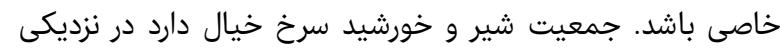

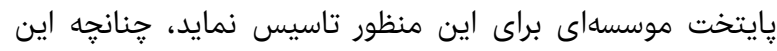

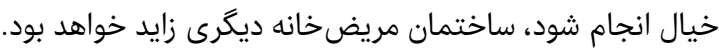

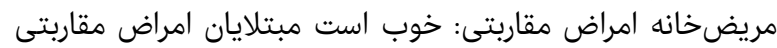

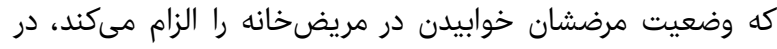

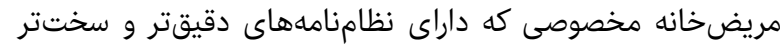

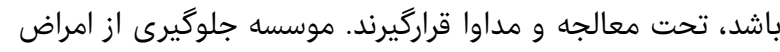

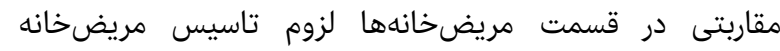

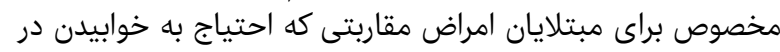

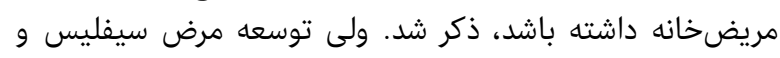

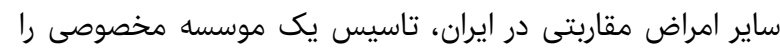

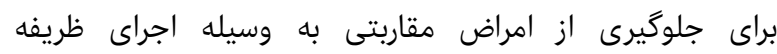

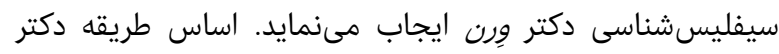

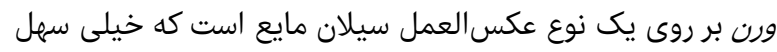

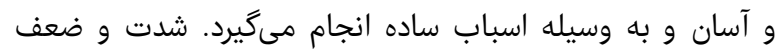
سيلان سرم خون يا مايع نخاع، شوكى كه به وسئ وسيله مقياس وناس

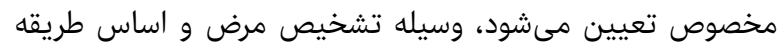

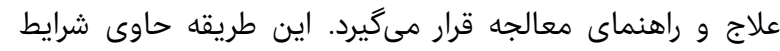

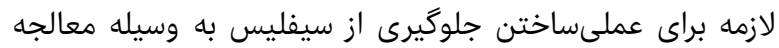

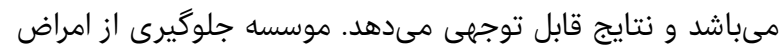

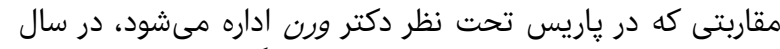

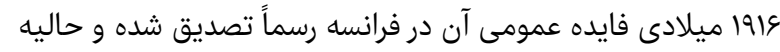

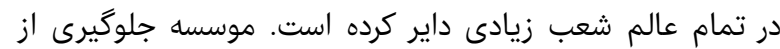

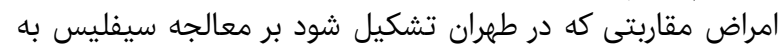

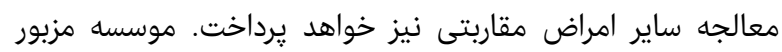

دواساز و قابله: دواسازان و قابلهانهاى دييلمه طهران، مايل به ترك درو

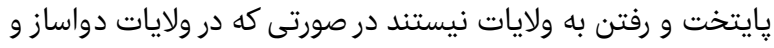

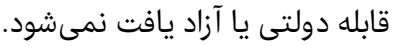

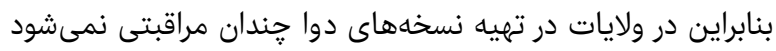

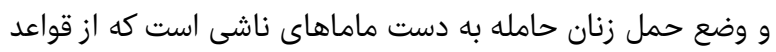

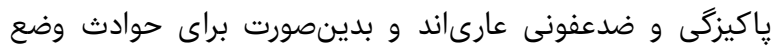

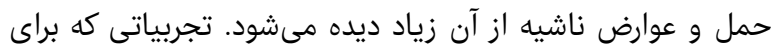

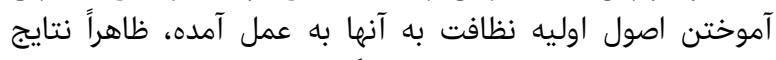

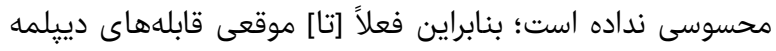

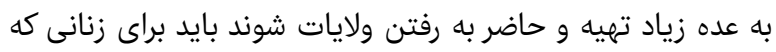

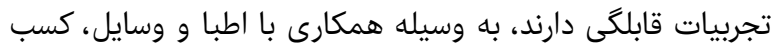

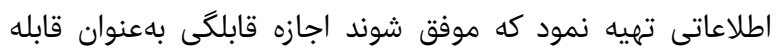

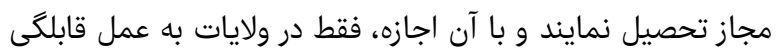

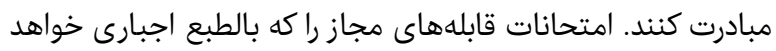

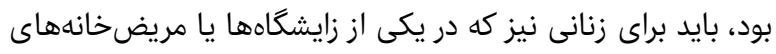

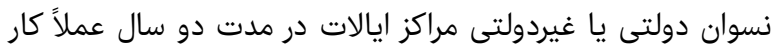

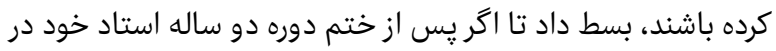

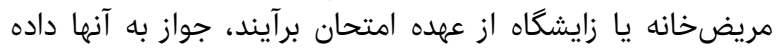

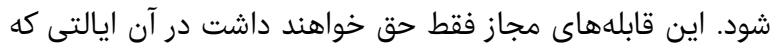

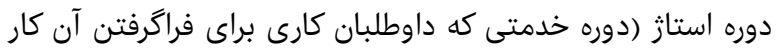

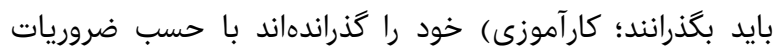

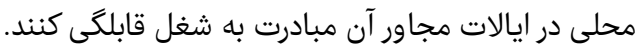

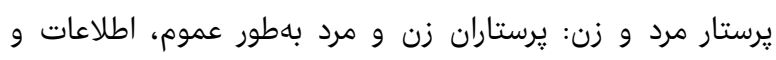

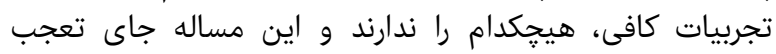

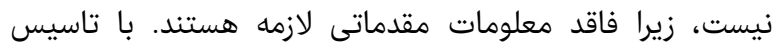

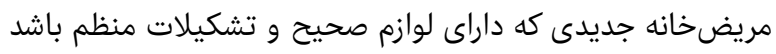
وسيله تعليم شاكردان يرستار مرد و زن، تحت شرائ لحرايط رضايتبخد

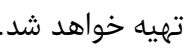
يرستاران مامور معاينه مَرضى

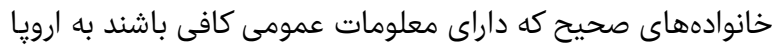

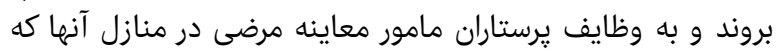

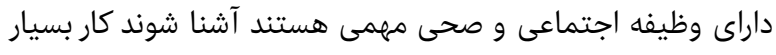

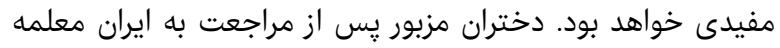

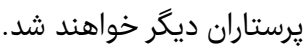

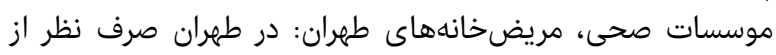

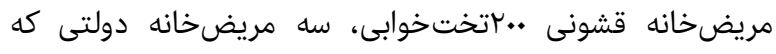

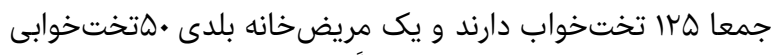

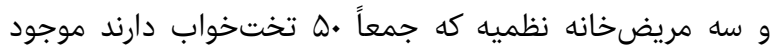

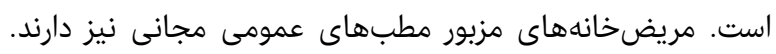

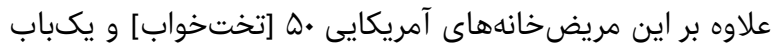

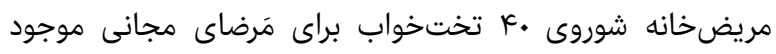

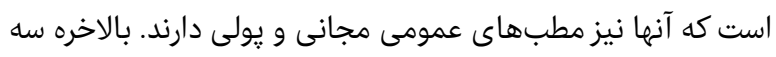

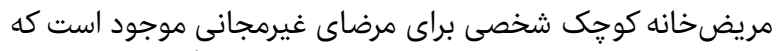

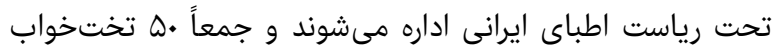

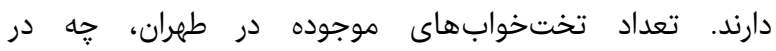

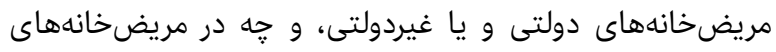

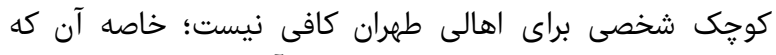

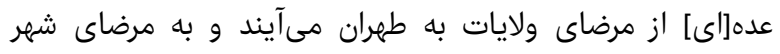

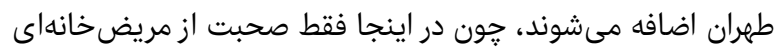

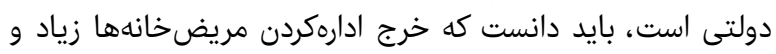

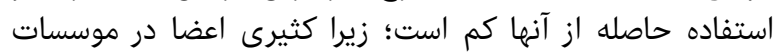

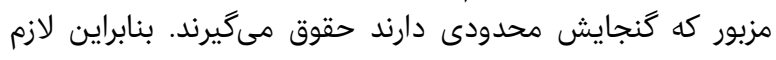




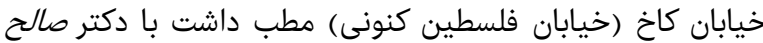

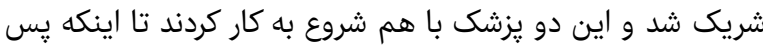

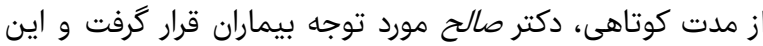

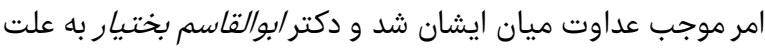

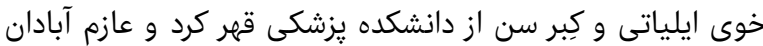

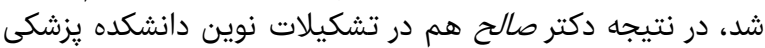

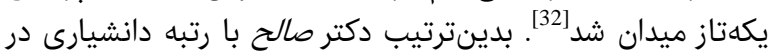

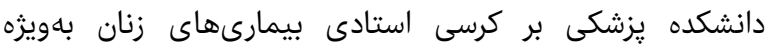

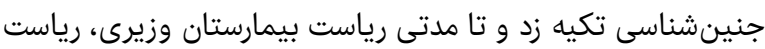

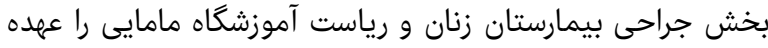

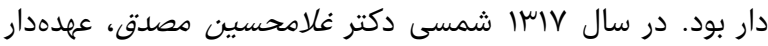

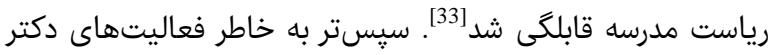

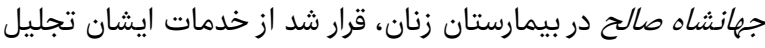

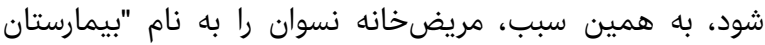

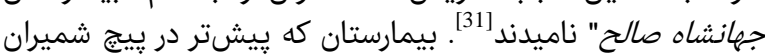

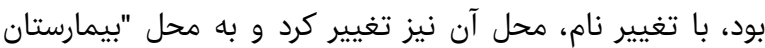

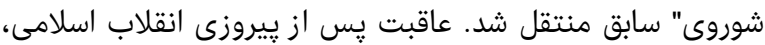

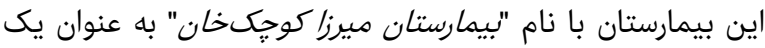

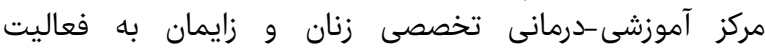

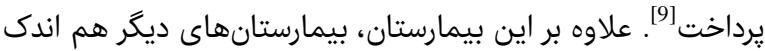

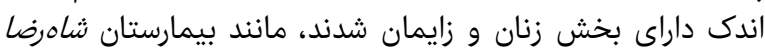

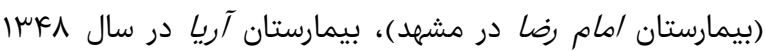

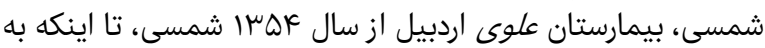

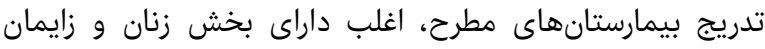

\section{نتيجه نيرى}

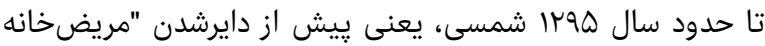

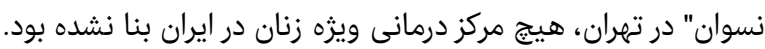

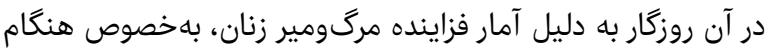

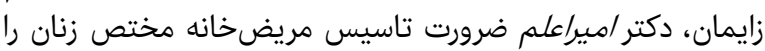

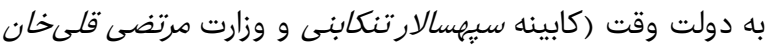

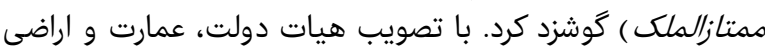

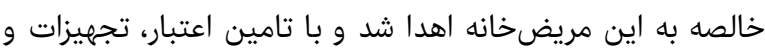

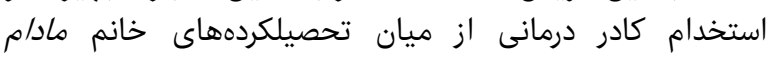

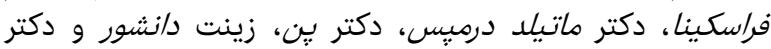

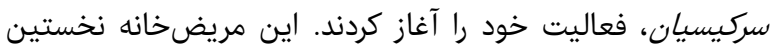

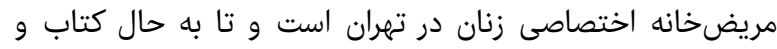

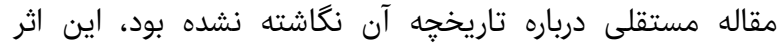

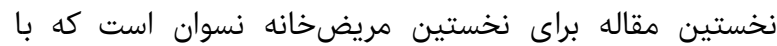
استفاده از اسناد آرشيوى و نشريه هاى عصر قاجار تدوين شد. نشان

تشكر و قدردانى: موردى از سوى نويسنده گزارش نشده است.

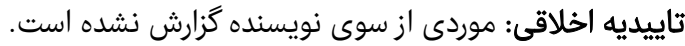

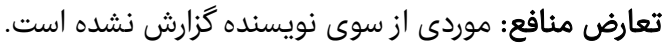

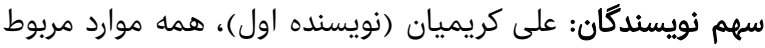

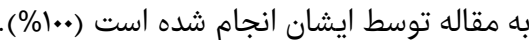
منابع مالى: موردى از سوى نويسنده كزارش نشده است است.

1- Tehran University of Medical Sciences. Analytical report of 4 year performance: on the occasion of the 70th
ممكن است تحت رياست يك نفر از اطباى جوان ايرانى كه در

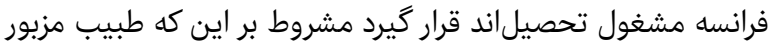

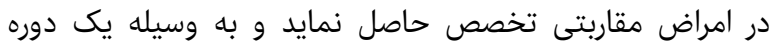

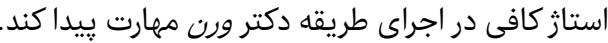

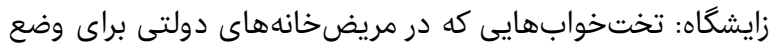

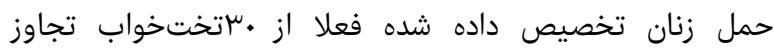

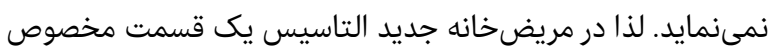

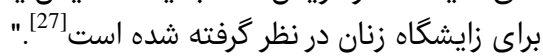

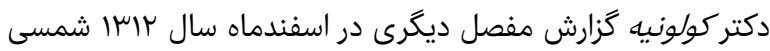

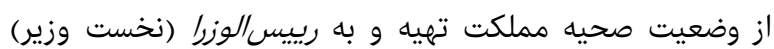

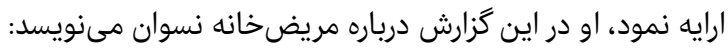

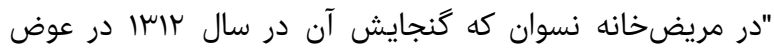

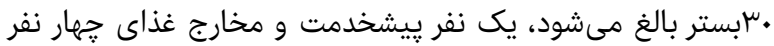

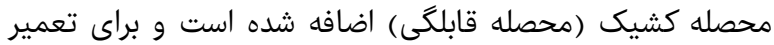

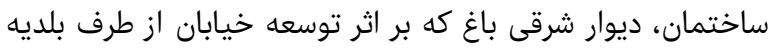

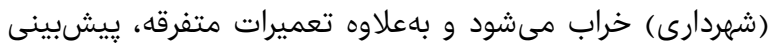

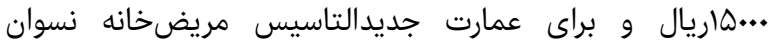
تقاضاى ....باريال اضافه اعتبار كرده است."

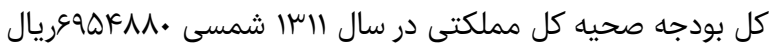

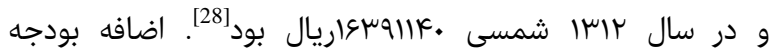

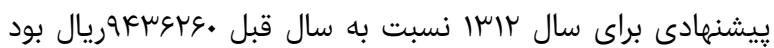

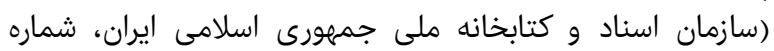

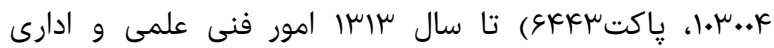

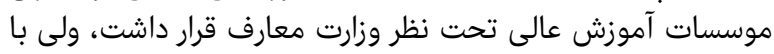

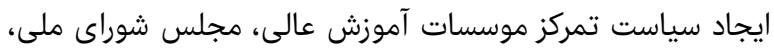

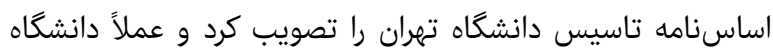

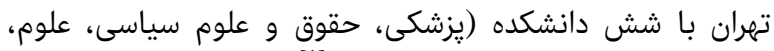

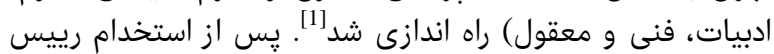

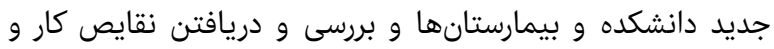

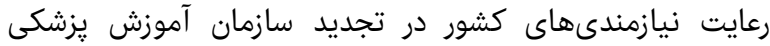

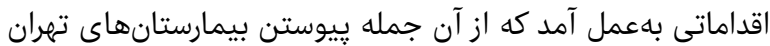

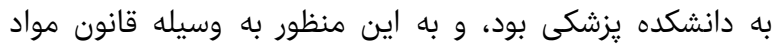
اصلاحى قانون تاسيس دانشكاه راجع به دانه دانشكده يز برشكى تصويب

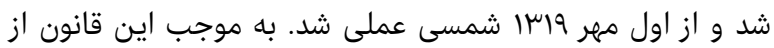

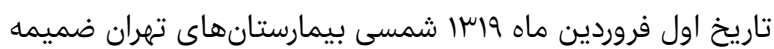

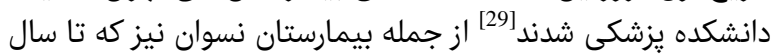

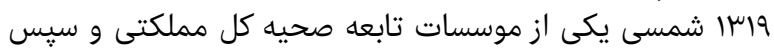

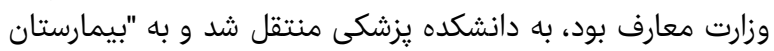

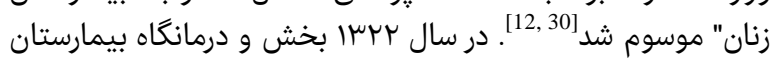

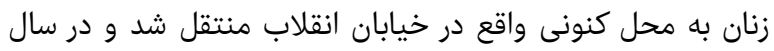

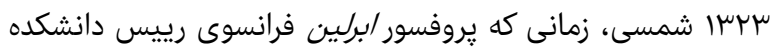

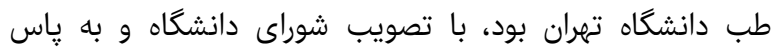

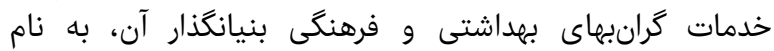

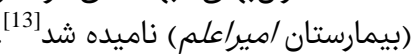

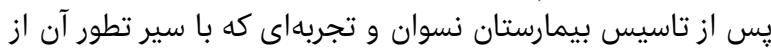

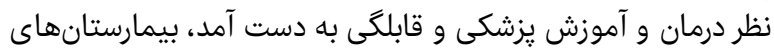

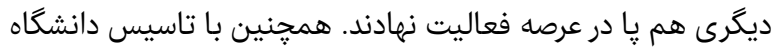

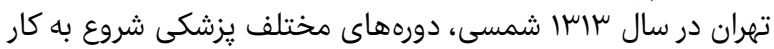

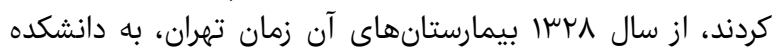

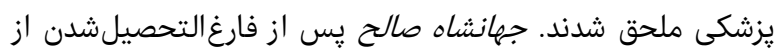

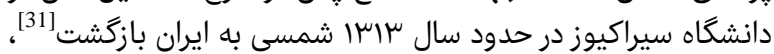

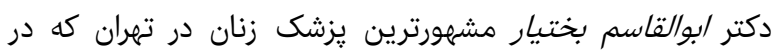


Iran. [Persian]

18- National Library and Archives of Iran. Accession No.240009267. Tehran: National Library and Archives of Iran. [Persian]

19- Farahani H. Calendar of Iran's contemporary history. Tehran: Political studies and research center; 2009. p.253. [Persian]

20- National Library and Archives of Iran. Accession No.2400032562. Tehran: National Library and Archives of Iran. [Persian]

21- National Library and Archives of Iran. Accession No.240095867. Tehran: National Library and Archives of Iran. [Persian]

22- National Library and Archives of Iran. Accession No.113009. Row No.54422. Tehran: National Library and Archives of Iran. [Persian]

23- National Library and Archives of Iran. Accession No.113009. Row No.52431. Tehran: National Library and Archives of Iran. [Persian]

24- Gilmour J. Iran's health situation report in Iran.

Tehran: Board of Conduct Health and social services

Press; 1975. [Persian]

25- National Library and Archives of Iran. Accession No.29728655. Tehran: National Library and Archives of Iran. [Persian]

26- National Library and Archives of Iran. Accession No.103004. Row No.6368. Tehran: National Library and Archives of Iran. [Persian]

27- National Library and Archives of Iran. Accession No.103004.Row No.6349. Tehran: National Library and Archives of Iran. [Persian]

28- National Library and Archives of Iran. Accession No.103004. Row No.6443. Tehran: National Library and Archives of Iran. [Persian]

29- General Directorate-Statistics Division. Statistics

Annual, 1938-1939. Tehran: Ministry of culture. p.p. 6-7. [Persian]

30- Salari H, Aalam A; Modern health in Iran. Tehran: Mehrab-e ghalam; 2013. p.17. [Persian]

31- Afshar I, Nikoyeh MC. Nadereh karan (mourning letter for Cultural and literary renowneds) 1925-2002. Tehran: Ghatreh; 2004. p.915. [Persian]

32- Movahedi MM. The Biography the famous cantemporary Iranian physicians. Tehran: Moaseseh Nashre Oloom va Fonoon; 1992. p.p.201-2. [Persian] 33- Agheli B. A Comprehensive dictionary of Contemporary Iranian and mititary Personalities. Tehran: Goftar- -Nashr-e Elmi; 2001. p.1452. [Persian] year of establishment of the Terhran University of Medical Sciences 1934-2009. Tehran: Tehran University Press; 2009. pp. 17-8. [Persian]

2- Ghasemi F. Pars Annual. Tehran: Amiarkabir Publication; 1964.p. 109. [Persian]

3- Namjooynik K. The history of military medicine. Tehran: Iran-e-Sabz; 2009. p.78. [Persian]

4- Serena C. Madam Carla serena's itinerary in Iran. Saeidi AA, Translator. Tehran: Zavar; 1983. 335p. [Persian]

5- Tehran Medical Science University. Sina hospital in the course of time. Tehran: Tehran University Press; 1999. p.13. [Persian]

6- Taryakian H. TalimolGhavabel: Midwifery training in Qajar. Tehran: Sarem Book; 2014. p.p.2-11. [Persian]

7- Tashayod AA. Aramaghan-e Javid or Doctor Aalam's Biography. Tehran: Islam's history magazine; 1961. p.61. [Persian]

8- Anonymous writer. Untitled. Shokoofeh Newspaper. 1915 Jun 6;3(12):2-4. [Persian]

9- Malek zadeh E. A glance to charirty affairs in Qajar Era. Tehran: Shahr-e Ray Islamic Azad University; 2006. p.131. [Persian]

10- Rostaee M. History of medicin in Iran. Tehran: National Library And Archives Of Iran; 2003. p.226. [Persian]

11- National Library And Archives Of Iran. Accession No 24094406. Tehran: National Library And Archives Of Iran. [Persian]

12- No'maani-pour GR. Research in the history of Imam Khomeini Hospital. Tehran: Tehran University of Medical Sciences; 1999. p.78. [Persian]

13- Yaghmaiee E. Science and education and culture Ministers of Iran. Tehran: Iran University Press; 1996. p.p.184-5. [Persian]

14- Mahbobi Ardekani H. History of New Civilization Institutions in Iran. Tehran: Tehran university Press; 1992. p.p.416-7. [Persian].

15- Ayati A. Preparations for Qajar dethronment and Reza-Khan's coronation by audigheh one the DarulFunun, French teachers and ms. dermps, Former student of the Eastern languages school. Tarikh-e Moaser-e Iran. 2004;8(29):31-49. [Persian]

16- National Library And Archives Of Iran. Accession No.297043704. Tehran: National Library And Archives Of Iran. [Persian]

17- National Library and Archives of Iran. Accession No.297011414. Tehran: National Library and Archives of 